\title{
Visualizations of Boger Fluid Flows in a 4:1 Square-Square Contraction
}

\author{
M. A. Alves \\ Depto. de Engenharia Química, CEFT, Faculdade de Engenharia da Universidade do Porto, 4200-465 Porto, Portugal \\ F. T. Pinho \\ Centro de Estudos de Fenómenos de Transporte, Depto. de Engenharia Mecânica, Universidade do Minho, Campus de \\ Azurém, 4800-058 Guimarães, Portugal
}

\section{P. J. Oliveira}

Depto. de Engenharia Electromecânica, Unidade Materiais Têxteis e Papeleiros, Universidade da Beira Interior, 6201-001 Covilhã, Portugal

DOI 10.1002/aic.10555

Published online August 12, 2005 in Wiley InterScience (www.interscience.wiley.com).

\begin{abstract}
Visualizations of the 3-D flow in a 4:1 square-square sudden contraction for two viscoelastic Boger fluids and two Newtonian fluids were carried out at low Reynolds numbers. In these creeping flow conditions, the vortex length remained unchanged for Newtonian fluids, whereas a nonmonotonic variation with flow rate was observed for the Boger fluids. Initially, the corner vortex slightly increased with flow rate to a local peak at a Deborah number of $D e_{2} \approx 6$, before decreasing significantly to a minimum at $D e_{2} \approx$ 15 (De ${ }_{2}$ is based on downstream characteristics). Finally, for Deborah numbers $>20$ there was intense vortex enhancement until a periodic flow was established at higher flow rates $\left(D e_{2} \approx 45-52\right)$. The strong elastic vortex enhancement was preceded by the appearance of diverging streamlines on the approach flow and, for the Boger fluid with higher polymer concentration, vortex enhancement took place through a lip vortex mechanism. () 2005 American Institute of Chemical Engineers AIChE J, 51: 2908-2922, 2005 Keywords: viscoelastic flow, Boger fluid, diverging flow, visualization, 3D contraction flow
\end{abstract}

\section{Introduction}

Flow visualizations have always been important in fluid mechanics and motivated a wealth of research in the field, as illustrated in Van Dyke's classic work An Album of Fluid Motion. ${ }^{1}$ They provide a clear insight of many phenomena and reinforce elaborate mathematics. Non-Newtonian fluids are usually more viscous than common Newtonian fluids and their flows are frequently investigated by flow visualization because

Correspondence concerning this article should be addressed to M. A. Alves at mmalves@fe.up.pt.

(C) 2005 American Institute of Chemical Engineers they tend to take place in the laminar regime. A compilation of flow visualization studies specifically for non-Newtonian fluids, was written by Boger and Walters in $1993,{ }^{2}$ and constitutes a representative sample of works published in this important subfield of fluid mechanics.

Sudden contraction flows are classical benchmark problems used in computational rheology, ${ }^{3}$ with the explicit assumption of two-dimensional (2-D) flow to simplify the simulations, and a large number of visualization studies in planar and axisymmetric contractions have been published in the literature. The flow behavior of non-Newtonian fluids in these simple configurations can be very surprising; there can be substantially different flow patterns for fluids with apparently similar 
rheological characteristics, and distinct patterns also arise in comparable configurations as a result of geometric differences (such as planar vs. axisymmetric).

The following paragraphs provide a review of relevant works in sudden contraction flows of axisymmetric, planar, and square-square type, and a summary of the main conclusions is presented in Table 1.

\section{Axisymmetric contractions}

For axisymmetric contractions, pioneering visualization studies with viscoelastic fluids were carried out by Cable and Boger $^{4-6}$ and Nguyen and Boger, ${ }^{7}$ who also reviewed previous work in the field. At low flow rates they observed that the salient corner vortex was controlled by viscous forces and a normalized length of 0.18 was measured, with the normalization based on the upstream pipe diameter. At higher flow rates a dramatic vortex growth was reported for all geometries (cf. Table 1) and for both shear-thinning and constant viscosity elastic fluids. At even higher Deborah numbers the flow became asymmetric and time dependent. At intermediate conditions Cable and Boger observed the onset of diverging flow upstream of the contraction plane and the simultaneous reduction of the salient vortex length, a phenomenon partially attributed to inertia. Fluid elasticity was considered the cause for the flow instabilities because the Reynolds numbers were well below those associated with transitions arising from inertial effects.

From the mid-1980s the 4:1 contraction became the focus of a variety of experimental and numerical work. The experimental work concentrated on the investigation of low Reynolds number flow transitions and elastic instabilities and relied on several techniques, as in McKinley et al. ${ }^{8}$ At that time the numerical methods were usually unable to predict accurately the subcritical steady flows and the emphasis was focused on improving the numerical techniques.

In 1986 Boger et al. ${ }^{9}$ investigated the behavior of two different Boger fluids having similar shear properties and yet found quite different vortex dynamics; for a polyisobutylene in polybutene fluid (PIB/PB) vortex enhancement was preceded by the growth of a lip vortex, whereas for polyacrylamide dissolved in corner syrup (PAA/CS) the lip vortex was absent. It was concluded that an additional measure of extensional properties had to be taken into account and in his 1987 review paper ${ }^{10}$ Boger suggested that parameter to be the extensional viscosity, and described in more detail the flow dynamics in the sudden contraction with increasing Deborah number. For some fluids only a convex corner vortex exists, growing in size and becoming concave as elasticity increases. For other fluids the corner vortex extends to the reentrant corner, and a lip vortex is formed. For high contraction ratios, the two vortices are initially separated, but similar distinct vortices were also seen by McKinley et al. ${ }^{8}$ in small contraction-ratio experiments. As the elasticity increases, the strength of the lip vortex grows at the expense of the corner vortex, whereas the length of the latter remains unchanged. Eventually, the lip vortex occupies the whole contraction plane region and a further increase in the Deborah number leads to a larger concave-shaped vortex. At even higher Deborah numbers a small pulsating lip vortex now appears and leads to unsteady behavior. All these features have been observed in axisymmetric contractions under conditions of negligible inertia.

Recent experimental investigations by Rothstein and McKinley ${ }^{11,12}$ clearly demonstrate the important role of extensional viscosity on the dynamics of vortex growth and on the associated enhanced pressure drop in contraction flows. They conjectured that the extra pressure drop results from an extra dissipative contribution to the elastic stress arising from a stress-conformation hysteresis in the nonhomogeneous extensional flow generated near the contraction plane. Such conjecture has implications on constitutive-equation modeling and led to the recent numerical simulations of Phillips et al. ${ }^{13}$ with a closed form of the adaptive length scale (ALS) model of Ghosh et al., ${ }^{14}$ which accounts for hysteresis of the conformation tensor. These authors were able to qualitatively predict large pressure drop enhancements, although there were still discrepancies in comparison with experiments.

\section{Planar contractions}

Investigations in planar contraction flows began soon after those in axisymmetric contractions and, although they confirmed some of the findings observed for the circular geometries, some notable discrepancies also emerged. Walters and Webster ${ }^{15}$ found no significant vortex activity for Boger fluids in the 4:1 case, in marked contrast to observations in 4.4:1 circular contractions. However, for shear-thinning fluids vortex growth was observed in both planar and axisymmetric geometries. To help clarify these differences, Evans and Walters ${ }^{16}$ studied the flows of shear-thinning and constant viscosity elastic fluids (aqueous solutions of polyacrylamide) through planar contractions (contraction ratios of $4: 1,16: 1$, and 80:1) and always found strong vortex enhancement for the shear-thinning fluids, even for the smaller contraction ratio, and difficulties in observing vortex activity for Boger fluids. They also reported that both the contraction ratio and fluid elasticity contributed to vortex enhancement with shear-thinning fluids. However, for the larger contraction ratios a lip vortex was seen and a growth mechanism similar to that previously found for circular dies was observed, although in the 4:1 planar contraction there was no sign of such a lip vortex. In a subsequent paper Evans and Walters ${ }^{17}$ looked at the behavior of shear-thinning fluids in the smaller contraction ratio of $4: 1$ to investigate whether a lip vortex mechanism of vortex growth was still at work. They found that for the less viscous/concentrated polymer solutions such lip vortex could be generated and that inertia played a critical role in separating the corner and lip vortices. Independent lip and corner vortices were also found in the numerical simulations of creeping flow by Alves et al. ${ }^{18,19}$ for a $4: 1$ contraction with Boger fluids represented by either the upper convected Maxwell (UCM) or the Oldroyd-B models.

The relevance of extensional viscosity in planar contraction flows was emphasized in the experimental investigations of White and Baird, ${ }^{20,21}$ who used two polymer melts: polystyrene (PS) and low-density polyethylene (LDPE). Whereas a vortex was observed for the LDPE, it was absent from PS flows and the difference was attributed to the distinct extensional viscosities, given their similar weak shear-thinning behavior. This was corroborated when the same authors later used a constitutive equation that represented accurately the measured extensional viscosity of both fluids, ${ }^{22}$ and were able to predict 
Table 1. Relevant Investigations of Viscoelastic Fluid Flow in Axisymmetric, Planar, and Square Contractions*

\begin{tabular}{|c|c|c|c|}
\hline Ref. & Authors (year) & $\begin{array}{l}\text { Flow Conditions and Test } \\
\text { Fluids }\end{array}$ & Main Conclusions \\
\hline $4-6$ & $\begin{array}{l}\text { Cable and Boger } \\
\quad(1978,1979)\end{array}$ & $\begin{array}{l}\text { Circular, } \beta=2,4 \\
\text { Shear-thinning fluids }\end{array}$ & $\begin{array}{l}\text { Vortex flow regime with vortex growth at low flow rates. } \\
\text { Divergent flow regime at intermediate flow rates and } \\
\text { inertial effects. } \\
\text { Unstable flow regime at large flow rates. }\end{array}$ \\
\hline 7 & $\begin{array}{l}\text { Nguyen and Boger } \\
\text { (1979) }\end{array}$ & $\begin{array}{l}\text { Circular, } 4<\beta<14.6 \\
\text { Boger and shear-thinning } \\
\quad \text { fluids }\end{array}$ & $\begin{array}{l}\text { Sequence of flow regimes referring to lip vortex } \\
\text { behavior: } \\
\text { (1) vortex growth; (2) asymmetric flow; (3) rotating } \\
\text { flow; (4) helical flow (pulsating). }\end{array}$ \\
\hline 15 & $\begin{array}{l}\text { Walters and Webster } \\
\text { (1982) }\end{array}$ & $\begin{array}{l}\text { Planar and circular, } \beta=4 \\
\text { Boger and shear-thinning } \\
\quad \text { fluids }\end{array}$ & $\begin{array}{l}\text { Boger fluids: substantial vortex activity in circular } \\
\text { contraction and virtually none in planar case. } \\
\text { Shear-thinning fluid: substantial vortex activity in circular } \\
\text { and planar contractions. } \\
\text { Rounding the corner dramatically changes flow. }\end{array}$ \\
\hline 24 & $\begin{array}{l}\text { Walters and Rawlinson } \\
\text { (1982) }\end{array}$ & $\begin{array}{l}\text { Planar, } \beta=13.3 \\
\mathrm{SQ} / \mathrm{SQ}, \beta=13.3 \\
\text { Boger fluids }\end{array}$ & $\begin{array}{l}\text { No noticeable vortex activity for the } 13.3: 1 \text { planar } \\
\text { contraction. } \\
\text { Significant vortices observed for the } 13.3: 13-\mathrm{D} \text { SQ/SQ } \\
\text { contraction. } \\
\text { Vortex enhancement with increasing flow rate. } \\
\text { Slight asymmetry at highest flow rates. }\end{array}$ \\
\hline 9 & Boger et al. (1986) & $\begin{array}{l}\text { Circular, } 4.4<\beta<16.5 \\
\text { Boger fluids }\end{array}$ & $\begin{array}{l}\text { Simultaneous lip and corner vortices, with lip vortex } \\
\text { dominating as De increases: } \\
\text { De }<3 \text { no influence of } \beta \text { on lip vortex; } \\
\text { De }>3 \text { influence of } \beta \text { on lip vortex. }\end{array}$ \\
\hline 16 & $\begin{array}{l}\text { Evans and Walters } \\
\text { (1986) }\end{array}$ & $\begin{array}{l}\text { Planar, } \beta=4,16,80 \\
\text { Boger and shear-thinning } \\
\quad \text { fluids } \\
\text { SQ/SQ, } \beta=16 \\
\text { Boger fluids }\end{array}$ & $\begin{array}{l}\text { Planar: } \\
\text { Boger fluids: difficulty in observing vortex activity. } \\
\text { Shear-thinning fluids: substantial vortex activity in all } \\
\text { cases. } \\
\text { Large } \beta \text { : vortex growth associated with lip vortex. } \\
\text { Small } \beta \text { : vortex growth is not associated with lip } \\
\text { vortex. } \\
\text { SQ/SQ: } \\
\text { Strong vortex enhancement for Boger fluids. }\end{array}$ \\
\hline 20 & $\begin{array}{l}\text { White and Baird } \\
\text { (1986) }\end{array}$ & $\begin{array}{l}\text { Planar, } \beta=5.9 \\
\text { Weakly shear-thinning } \\
\text { melts }\end{array}$ & $\begin{array}{l}\text { Vortex growth for LDPE due to early onset of shear- } \\
\text { thinning and strain hardening extensional viscosity. } \\
\text { No vortex growth for PS which has no strain hardening } \\
\text { extensional viscosity. } \\
\text { Relevance of extensional viscosity. }\end{array}$ \\
\hline 21 & $\begin{array}{l}\text { White and Baird } \\
\text { (1988) }\end{array}$ & $\begin{array}{l}\text { Planar, } \beta=4,8 \\
\text { Weakly shear thinning } \\
\text { polymer melts (LDPE, } \\
\text { PS) }\end{array}$ & $\begin{array}{l}\text { Confirmation of the observations of White and Baird }{ }^{20} \\
\text { for lower and higher contraction ratios. }\end{array}$ \\
\hline 22 & $\begin{array}{l}\text { White and Baird } \\
\text { (1988) }\end{array}$ & $\begin{array}{l}\text { Planar, } \beta=4,8 \\
\text { Numerical, Full PTT, } \zeta \neq \\
\quad 0\end{array}$ & $\begin{array}{l}\text { Simulations confirm experiments of White and Baird }{ }^{21} \text { in } \\
\text { terms of streamlines and birefringence. } \\
\text { Size and intensity of vortex determined by parameter } \varepsilon \text {, } \\
\text { which controls extensional viscosity in the PTT } \\
\text { model. }\end{array}$ \\
\hline 17 & $\begin{array}{l}\text { Evans and Walters } \\
\text { (1989) }\end{array}$ & $\begin{array}{l}\text { Planar, } \beta=4 \\
\text { Shear-thinning fluids }\end{array}$ & $\begin{array}{l}\text { For some fluids there are lip and corner vortices, with the } \\
\text { former responsible for the vortex enhancement } \\
\text { mechanisms, as for large } \beta \text {. } \\
\text { For mobile fluids inertia separates corner and lip vortices. }\end{array}$ \\
\hline 8 & McKinley et al. (1991) & $\begin{array}{l}\text { Circular, } 2<\beta<8 \\
\text { Boger fluid }\end{array}$ & $\begin{array}{l}\text { Sequence of flow regimes near the lip vortex: (1) stable; } \\
\text { (2) time periodic; (3) quasi-periodic; (4) aperiodic. } \\
\text { Time-dependent } 3 \text {-D flow for } 2<\beta<5 \text { at high flow } \\
\text { rates. } \\
\text { Rounding corner delays transitions. }\end{array}$ \\
\hline 46 & $\begin{array}{l}\text { Boger and Binington } \\
\text { (1994) }\end{array}$ & $\begin{array}{l}\text { Circular, } \beta=4 \\
\text { Sharp and rounded } \\
\quad \text { reentrant corner } \\
\text { Boger fluids }\end{array}$ & $\begin{array}{l}\text { Each of the two fluids studied react differently to the } \\
\text { rounded corner: dramatic changes are observed for } \\
\text { the polyacrylamide based Boger fluid, in deep } \\
\text { contrast to less dramatic changes observed for the } \\
\text { polyisobutylene based fluid. }\end{array}$ \\
\hline 47 & $\begin{array}{l}\text { Purnode and Crochet } \\
\text { (1996) }\end{array}$ & $\begin{array}{l}\text { Numerical simulations } \\
\quad \text { with a FENE-P model } \\
\text { Planar, } \beta=4,16,80 \\
\text { Shear-thinning fluids }\end{array}$ & $\begin{array}{l}\text { Predictions qualitatively match the experimental results } \\
\text { of Evans and Walters. }{ }^{16,17} \\
\text { Lip vortex not associated with inertia. }\end{array}$ \\
\hline 26 & $\begin{array}{l}\text { Mompean and Deville } \\
\text { (1997) }\end{array}$ & $\begin{array}{l}\text { Numerical, Oldroyd-B } \\
\text { model } \\
\text { 2-D, } \beta=4 \\
\text { 3-D planar } \beta=4\end{array}$ & $\begin{array}{l}\text { 2-D: no prediction of lip vortex; decrease of corner } \\
\text { vortex size with Deborah number. } \\
\text { 3-D: Corner vortex in center plane always smaller than } \\
\text { in } 2 \mathrm{D} \text { case. }\end{array}$ \\
\hline
\end{tabular}


Table 1. Relevant Investigations of Viscoelastic Fluid Flow in Axisymmetric, Planar, and Square Contractions* (Continued)

\begin{tabular}{|c|c|c|c|}
\hline Ref. & Authors (year) & $\begin{array}{c}\text { Flow Conditions and Test } \\
\text { Fluids }\end{array}$ & Main Conclusions \\
\hline 27 & Xue et al. (1998) & $\begin{array}{l}\text { Numerical } \\
\text { 2-D: UCM } \\
\text { 3-D planar: Boger and } \\
\text { shear-thinning fluids } \\
\text { (UCM, PTT with } \zeta \neq \\
\text { 0) }\end{array}$ & $\begin{array}{l}\text { 2-D: Lip and corner vortex growth mechanisms } \\
\text { depending on elasticity and Deborah numbers. } \\
\text { Appearance of lip vortex depends on polymer } \\
\text { viscosity and is promoted by inertia. } \\
\text { 3-D planar } \\
\text { - UCM: confirms presence of lip vortex for some flow } \\
\text { conditions. } \\
\text { - PTT: qualitative agreement with experiments of } \\
\text { Quinzani et al.48 }\end{array}$ \\
\hline 25 & Xue et al. (1998) & $\begin{array}{l}\text { Numerical } \\
\text { 2D and } 3 \mathrm{D} \text { SQ/SQ, } \beta=4 \\
\text { Boger and shear-thinning } \\
\text { fluids: UCM, PTT }(\zeta \neq \\
0)\end{array}$ & $\begin{array}{l}\text { Relevance of transient extensional behavior along } \\
\text { centerline. In 3-D vortex activity correlates well } \\
\text { with steady extensional properties, but not in } 2-\mathrm{D} \text {. }\end{array}$ \\
\hline 11 & $\begin{array}{l}\text { Rothstein and } \\
\text { McKinley (1999) }\end{array}$ & $\begin{array}{l}\text { Circular, } \beta=4 \\
\text { Boger fluid }\end{array}$ & $\begin{array}{l}\text { Measurement of enhanced pressure drop. It is suggested } \\
\text { that this is attributable to an additional dissipative } \\
\text { contribution of polymer stress manifested in stress } \\
\text { conformation hysteresis. }\end{array}$ \\
\hline 18 & Oliveira and Pinho & Planar, numerical & Lip vortex growth mechanism for UCM fluid. \\
\hline 42 & (1999); Alves et al. & $\beta=4$ & No lip vortex for PTT fluid. \\
\hline 43 & $(2000)$ & UCM and PTT fluids & $\begin{array}{l}\text { Streamline divergence for high Deborah flows, enhanced } \\
\text { by inertial effects (UCM). } \\
\text { Importance of mesh refinement and discretization } \\
\text { schemes for numerical accuracy. }\end{array}$ \\
\hline 12 & $\begin{array}{l}\text { Rothstein and } \\
\text { McKinley (2001) }\end{array}$ & $\begin{array}{l}\text { Circular, } 2<\beta<8 \\
\text { Various curvatures of } \\
\quad \text { corner } \\
\text { Boger fluid }\end{array}$ & $\begin{array}{l}\beta=2 \text { : steady elastic lip vortex } \\
4 \leq \beta \leq 8 \text { : no lip vortex observed, only corner vortex. } \\
\text { Rounding the reentrant corner leads to shifts in the onset } \\
\text { of flow transitions to larger Deborah numbers. } \\
\text { The role of contraction ratio on vortex growth dynamics } \\
\text { is rationalized by using a dimensionless ratio of the } \\
\text { elastic normal stress difference in steady shear flow } \\
\text { to that in transient uniaxial extension. }\end{array}$ \\
\hline 23 & $\begin{array}{l}\text { Nigen and Walters } \\
\text { (2002) }\end{array}$ & $\begin{array}{l}\text { Planar and circular } \\
2 \leq \beta \leq 32 \\
\text { Boger fluids }\end{array}$ & $\begin{array}{l}\text { Planar case: no sign of steady vortex enhancement } \\
\text { Circular: lip mechanism responsible for vortex growth } \\
\text { and enhanced pressure drop. }\end{array}$ \\
\hline 19 & Alves et al. (2003) & $\begin{array}{l}\text { Planar, numerical; } \beta=4 \\
\text { Highly refined mesh } \\
\text { Oldroyd-B and PTT } \\
\text { (linear and exponential) } \\
\text { models }\end{array}$ & $\begin{array}{l}\text { Lip vortex enhancement for Oldroyd-B fluid } \\
\text { accompanied by decrease in corner vortex. } \\
\text { Intense corner vortex growth for linear PTT and no lip } \\
\text { vortex. } \\
\text { High Deborah number simulations for PTT models. }\end{array}$ \\
\hline
\end{tabular}

$* \beta$ represents the contraction ratio. Works are presented in chronological order.

numerically, at least qualitatively, the different vortex patterns observed.

The surprisingly different behavior of Boger fluids in circular and planar contractions has been further studied by Nigen and Walters. ${ }^{23}$ Experiments in both types of contraction were conducted with Newtonian and Boger fluids having identical shear viscosities and it was demonstrated that, although there were higher extensional strain rates in the planar geometry than in the circular die, virtually no elastic vortex enhancement was found in the former geometry in contrast to the latter. Given that the vortex dynamics is a complex function of strain rates, strains, and molecular conformation histories, ${ }^{12}$ these differences are not so surprising.

\section{Square-square contractions}

Experiments with flows through square-square contractions are scarce, partly because they are more complex but also because of their inadequacy to be used for comparison with 2-D simulations. In their 1982 experiments, Walters and Rawlinson $^{24}$ reported similarities between the flows through circular and square-square contractions. In particular, the differ- ences found between flows of Boger fluids in planar and circular contractions were also seen for planar and 13.3:1 square-square contractions and at intermediate Deborah numbers a diverging flow was seen upstream of the contraction as originally observed by Cable and Boger ${ }^{4}$ for circular geometries.

In the square duct contraction, and in contrast to the 2-D planar case, isopressure lines can close in the cross-stream directions, as in the axisymmetric geometry, but there are now normal stress imbalances leading to secondary flows. The dynamics of the vortices in combination with these new secondary flow structures and fluid elasticity are still to be well characterized and understood.

In view of the above, it comes as no surprise that flow predictions of square-square contraction flows are virtually inexistent except for the work of Xue et al.,25 to be discussed below. Most of the existing three-dimensional (3-D) viscoelastic flow simulations in contractions basically considered the 2-D planar contraction extending along the spanwise direction and so the 3-D effects were attributed only to the presence of end walls. Some computations of such planar 3-D contraction 
flows (in fact, quasi-2-D) were presented by Mompean and Deville ${ }^{26}$ and Xue et al. ${ }^{27}$; their intention was mainly to illustrate the capabilities of their finite-volume methods in 3-D simulations, so they did not comment on the results of their calculations in relation to 3-D effects and in fact the detailed 3-D flow structure was not well resolved. The only 3-D effect mentioned by Xue et al. ${ }^{27}$ was that the average velocity in a 3 -D channel differs from the average velocity in a 2-D channel, and therefore the Deborah number should be modified accordingly.

In a second article, Xue et al. ${ }^{25}$ tackled the actual 3-D square-square contraction using the Phan-Thien-Tanner model (PTT) (with a nonzero second normal stress difference coefficient) and UCM constitutive equations. They found strong vortex enhancement for both fluid models, in contrast to the results for the planar contraction where only the PTT fluid (shear-thinning fluid) exhibited vortex enhancement. These contrasting behaviors mirror those observed experimentally for axisymmetric and planar contraction flows, and are explained by the 3-D nature of circular and square-square contractions. The numerical investigations of Xue et al. ${ }^{25}$ related the calculated flow dynamics with the transient extensional viscosity of the fluids, but nothing was reported regarding unexpected secondary flows in the contraction region or the onset of flow instabilities; they did mention, however, the existence of the well-known secondary flow in the fully developed straight upstream and downstream noncircular ducts.

In conclusion, the vast majority of experimental work on contraction flows of viscoelastic liquids has been on axisymmetric and (approximately) planar configurations, with the expectation that 2-D numerical simulations would allow for adequate predictions. A square-square contraction arrangement is a good compromise between geometric simplicity and complex 3-D flow structure, and appears as a good candidate for a prototype 3-D test case that is necessary for validating numerical 3-D codes. However, before embarking on the heavy task of performing full 3-D simulations of such viscoelastic flows, both under steady and transient conditions, a thorough experimental investigation is required. This is the motivation for the present experimental work, which concentrates on characterizing the flow patterns in square-square contractions of elastic fluids having a constant shear viscosity.

\section{Experimental Setup}

The experimental apparatus is depicted in Figure 1. The rig consisted of two consecutive square ducts (length: 1000 and $300 \mathrm{~mm}$ ) and a vessel. The sides of the square ducts were $2 H_{1}$ $=24.0 \mathrm{~mm}$ and $2 \mathrm{H}_{2}=6.0 \mathrm{~mm}$, respectively, thus defining the $4: 1$ contraction ratio. The flow rate was set by an adequate control of applied pressure on the upper duct and frictional losses in the long coiled pipe ( $\mathrm{T}$ in Figure 1) located between the smaller duct and the vessel, at the bottom of the rig. To achieve low flow rates the coiled pipe was $8 \mathrm{~m}$ long and had a diameter of $4 \mathrm{~mm}$, whereas for higher flow rates the diameter of the coiled pipe was $6 \mathrm{~mm}$. Applied pressure was kept between 0.5 and 4 bar, and the dashed lines in Figure 1 represent the pressurized air lines. This flow arrangement adequately controlled the flow rate without significant constrictions, such as valves, that would eventually degrade the poly-

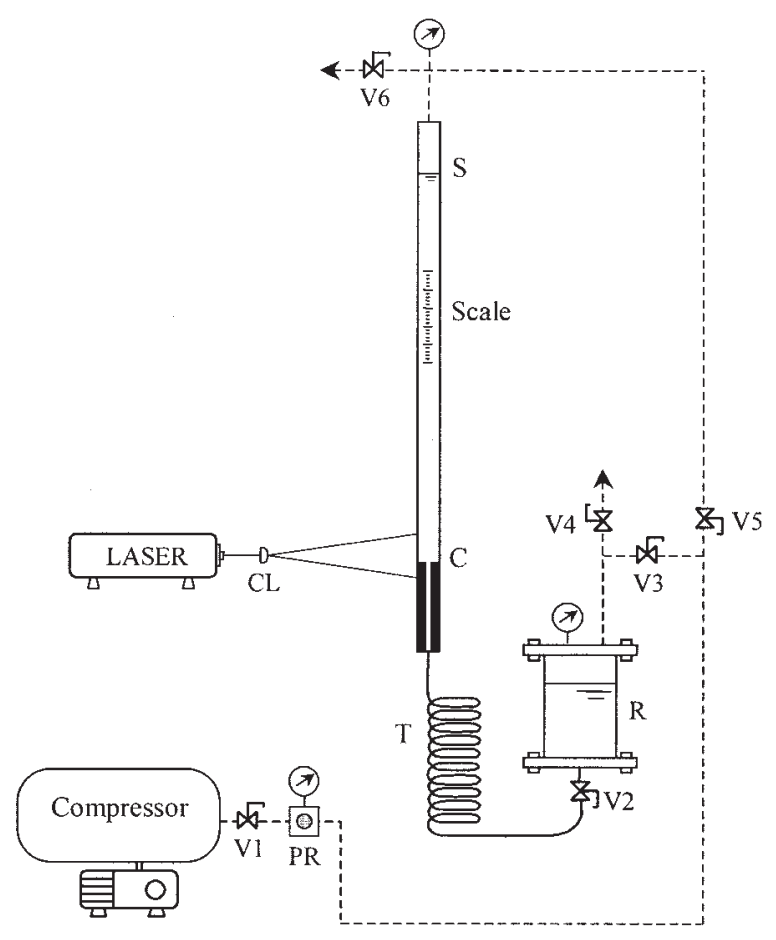

Figure 1. Flow rig.

$\mathrm{PR}$, pressure regulator; V1 to V6, ball valves; R, reservoir; $\mathrm{CL}$, cylindrical lens; $\mathrm{T}$, long coiled pipe; $\mathrm{S}$, free surface; $\mathrm{C}$, contraction plane.

mer molecules. The flow rate was measured by a stopwatch and the passage of the liquid-free surface at two marks in the upper duct. In all tests the fluid temperature was measured and the fluid properties were taken from the rheometric master curves shown in the next section. To improve the quality of the visualizations the rig was placed inside a dark room.

A $10 \mathrm{~mW}$ He-Ne laser light source was used to visualize the flow patterns. The laser beam passed through a cylindrical lens to generate a light sheet illuminating highly reflective tracer particles suspended in the fluid. These were $10 \mu \mathrm{m}$ PVC particles (at a concentration of about $15 \mathrm{mg} / \mathrm{kg}$ fluid) added during the preparation of the fluid. The path lines formed were recorded using long time exposure photography with a conventional camera (Canon EOS300 with a macro EF100 mm $\mathrm{f} / 2.8$ lens), as sketched in Figure 2, which includes a schematic representation of the test section. The terminal velocity of the PVC particles was negligible: assuming Stokes flow conditions it was estimated to be $0.15 \mu \mathrm{m} / \mathrm{s}$ in the less viscous Newtonian fluid used (N85), which is three orders of magnitude smaller than the minimum flow bulk velocity.

The shear viscosity $(\eta)$ and the first normal stress difference coefficient $\left(\Psi_{1}\right)$ in steady shear flow, and the storage and loss moduli $\left(G^{\prime}, G^{\prime \prime}\right)$ in dynamic shear flow were used to characterize the rheology of the Boger fluids. These properties were measured with an AR2000 rheometer from TA Instruments, using a cone-plate setup with $40 \mathrm{~mm}$ diameter and $2^{\circ}$ angle. A falling ball viscometer from Gilmont Instruments (model GV2200) was also used for some viscosity measurements with the Newtonian fluid N85. 


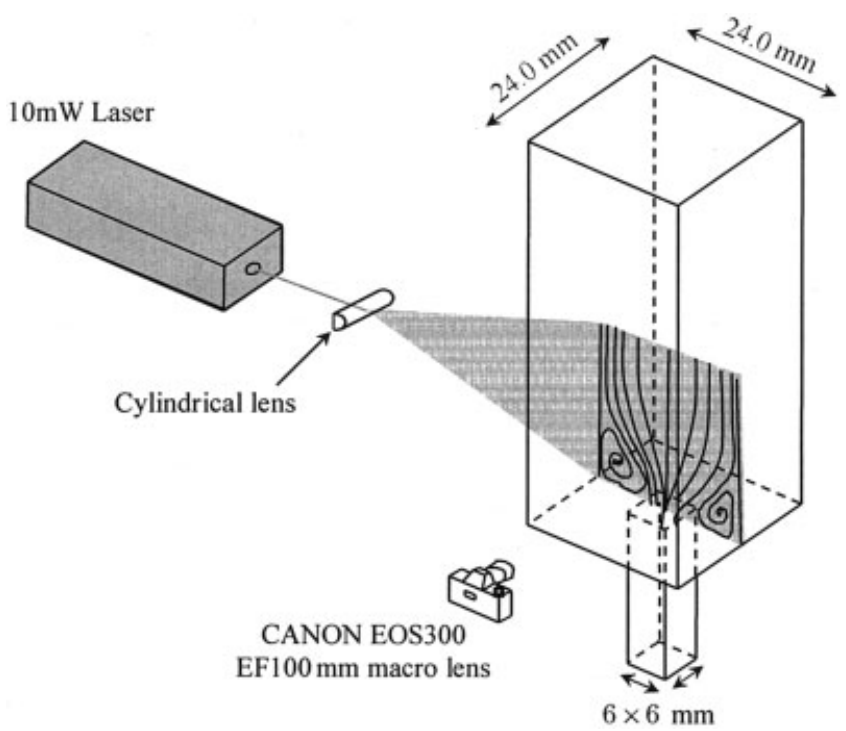

Figure 2. Flow visualization technique and details of the test section.

\section{Rheological Characterization of the Fluids}

Four fluids based on mixtures of glycerin and water were investigated: two viscous Newtonian fluids (N85 and N91) and two viscoelastic Boger fluids (PAA100 and PAA300). Their compositions, densities, and zero-shear rate viscosities are listed in Table 2. The Boger fluids were prepared by dissolving a small amount of polyacrylamide (PAA; Separan AP30 produced by SNF Floerger) in the Newtonian solvent N91. To minimize the intensity of shear thinning a small amount of $\mathrm{NaCl}$ was added, as described in detail in Stokes. ${ }^{28}$ To reduce bacteriological degradation of the solutions the biocide Kathon LXE, produced by Rohm and Haas, was also added. The fluid densities were measured at $21.2^{\circ} \mathrm{C}$ using a picnometer.

\section{Newtonian fluids}

For the N85 fluid the measured shear viscosity was $\eta=$ $0.125 \mathrm{~Pa} \cdot \mathrm{s}$ at $18^{\circ} \mathrm{C}$, the temperature at which the visualizations took place. For the N91 fluid the rheometer was used to measure the shear viscosity at temperatures ranging from 15.9 to $25.0^{\circ} \mathrm{C}$. This second Newtonian fluid, which served as solvent for the PAA solutions, was also used to evaluate the accuracy of the rheometer and to estimate the base noise level in dynamic tests (represented as the dashed baseline of $2 G^{\prime}$ in Figures $3 \mathrm{~b}$ and $4 \mathrm{~b}$ ). For $N_{1}$, the measurements at $\dot{\gamma}<100 \mathrm{~s}^{-1}$ indicated a zero reading within experimental uncertainty, as they should. The uncertainty in measuring $N_{1}$ was of the order of $\pm 10 \mathrm{~Pa}$, in agreement with the specifications of the manufacturer for the cone-plate geometry used. For $\dot{\gamma}>100 \mathrm{~s}^{-1}$
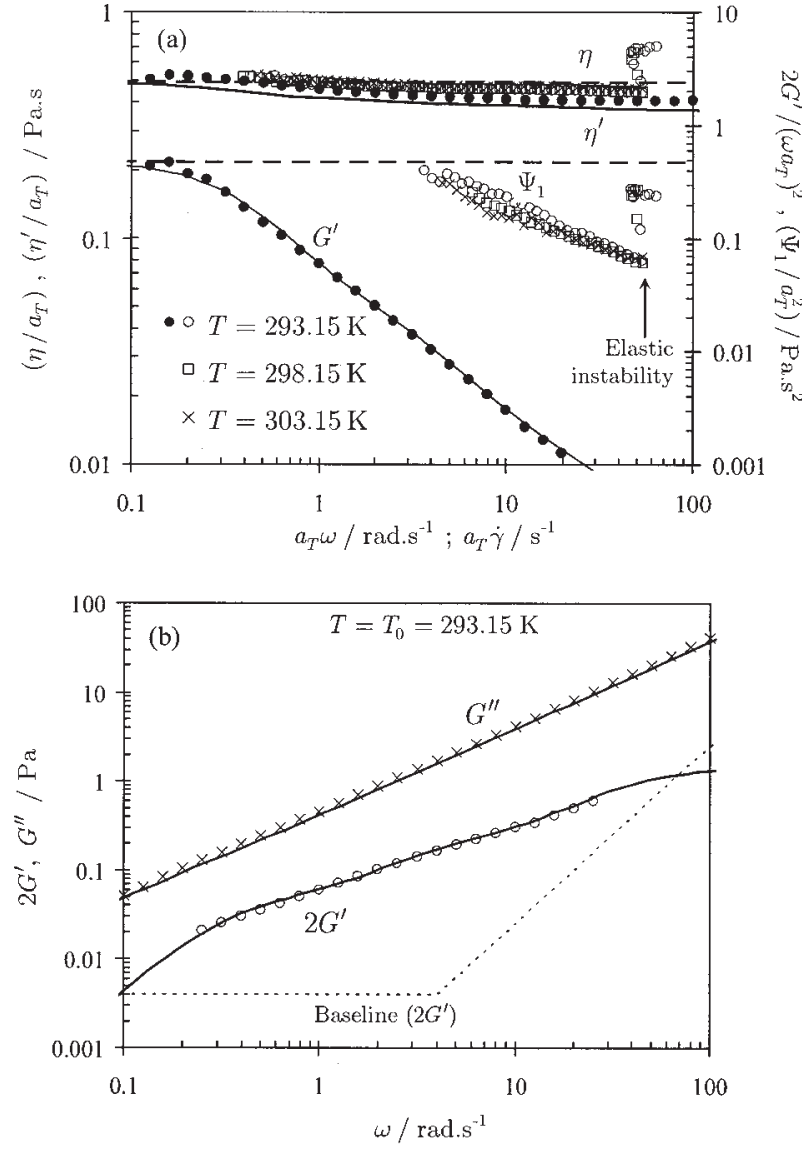

Figure 3. Material parameters in steady and dynamic shear flow for the PAA100 fluid.

(a) Open symbols for shear viscosity and first normal stress difference coefficient; solid symbols for $G^{\prime}$ and $\eta^{\prime}$; (b) comparison between $G^{\prime}$ and $G^{\prime \prime}$ data (symbols) and fitting by three-mode Oldroyd-B model (solid lines).

inertial effects became important, and negative values of $N_{1}$ were measured. This inertial effect for Newtonian fluids was well predicted by the following equation ${ }^{29}$ :

$$
N_{1, \text { inertia }}=-0.15 \rho \omega^{2} R^{2}
$$

where $\omega$ and $R$ represent the angular velocity and the radius of the cone, respectively.

The effect of temperature on the shear viscosity for the N91 fluid is well described by an Arrhenius equation, defining a shift factor $a_{T}$ of the form

$$
\ln \left(a_{T}\right)=\ln \frac{\eta(T)}{\eta\left(T_{0}\right)}=\left[\frac{\Delta H}{R}\left(\frac{1}{T}-\frac{1}{T_{0}}\right)\right]
$$

\begin{tabular}{|c|c|c|c|c|c|c|c|}
\hline Designation & $\begin{array}{l}\text { PAA } \\
(\mathrm{ppm})\end{array}$ & $\begin{array}{c}\text { Glycerin } \\
(\%)\end{array}$ & $\begin{array}{c}\text { Water } \\
(\%)\end{array}$ & $\begin{array}{c}\mathrm{NaCl} \\
(\%)\end{array}$ & $\begin{array}{c}\text { Kathon } \\
\text { (ppm) }\end{array}$ & $\begin{array}{c}\rho \\
\left(\mathrm{kg} / \mathrm{m}^{3}\right)\end{array}$ & $\eta_{\mathrm{o}}(\mathrm{Pa} \cdot \mathrm{s})$ \\
\hline N85 & - & 84.99 & 15.01 & - & 25 & 1221 & $0.125\left(18^{\circ} \mathrm{C}\right)$ \\
\hline N91 & - & 90.99 & 7.51 & 1.50 & 25 & 1250 & $0.367\left(20^{\circ} \mathrm{C}\right)$ \\
\hline PAA100 & 100 & 90.99 & 7.50 & 1.50 & 25 & 1249 & $0.487\left(20^{\circ} \mathrm{C}\right)$ \\
\hline PAA300 & 300 & 90.97 & 7.50 & 1.50 & 25 & 1247 & $0.735\left(20^{\circ} \mathrm{C}\right)$ \\
\hline
\end{tabular}

Table 2. Composition and Properties of the Fluids (Mass Concentrations) 

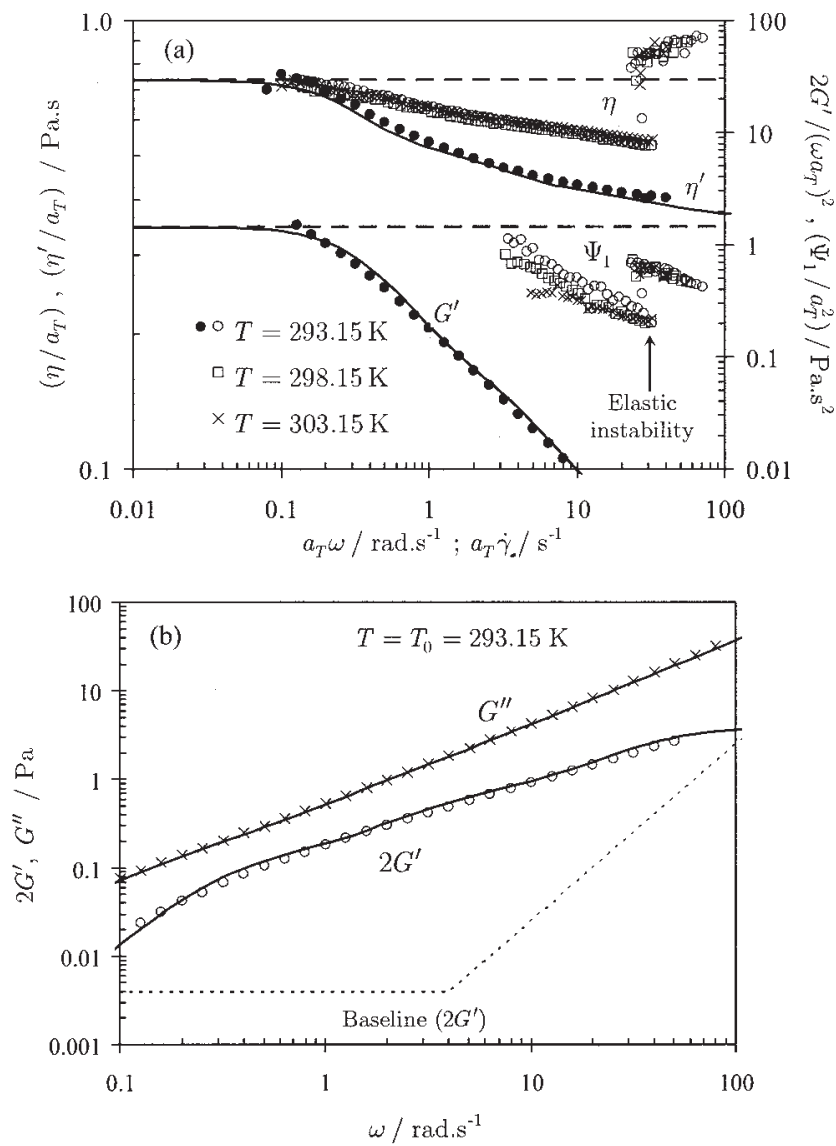

Figure 4. Material parameters in steady and dynamic shear flow for the PAA300 fluid.

(a) Open symbols for shear viscosity and first normal stress difference coefficient; solid symbols for $G^{\prime}$ and $\eta^{\prime}$; (b) comparison between $G^{\prime}$ and $G^{\prime \prime}$ data (symbols) and fitting by three-mode Oldroyd-B model (solid lines).

where $\eta\left(T_{0}\right)$ represents the viscosity at the reference absolute temperature $T_{0}$, here taken as $T_{0}=293.15 \mathrm{~K}$. Fitting this equation to the experimental data gave $\Delta H / R=6860 \mathrm{~K}$ and $\eta\left(T_{0}\right)=0.367 \mathrm{~Pa} \cdot \mathrm{s}$ (more details can be found in Alves ${ }^{30}$ ).

Generally, the shift factor $a_{T}$ is defined as ${ }^{31}$

$$
a_{T}=\frac{\eta_{0}(T)}{\eta_{0}\left(T_{0}\right)} \frac{T_{0}}{T} \frac{\rho_{0}}{\rho}
$$

where $\eta_{0}\left(T_{0}\right)$ designates the zero shear-rate viscosity at the reference temperature $T_{0}$, and $\rho$ and $\rho_{0}$ are the fluid densities at temperatures $T$ and $T_{0}$, respectively. When the range of temperatures is limited the definition of the shift factor can be simplified by dropping the effects of density and temperature ratios $^{31}$ and thus Eq. 2 is the form adopted in this work, with $\eta(T)=\eta_{0}(T)$ and $\eta\left(T_{0}\right)=\eta_{0}\left(T_{0}\right)$.

\section{Boger fluids}

For the Boger fluids the steady shear properties were measured at temperatures ranging from 15.3 to $30.0^{\circ} \mathrm{C}$. The timetemperature superposition principle was found to be valid for both fluids and was used to build master curves. The value of
$\Delta H / R$ obtained for the solvent was found to be adequate for the two Boger fluids. The reduced rheological quantities (subscript $r$ ) thus become as defined by Eqs. $4 \mathrm{a}-4 \mathrm{~d}^{32}$

$$
\begin{aligned}
& \omega_{r} \equiv \omega\left(T_{0}\right)=a_{T} \omega(T) \quad \dot{\gamma}_{r} \equiv \dot{\gamma}\left(T_{0}\right)=a_{T} \dot{\gamma}(T) \\
& G_{r}^{\prime} \equiv G^{\prime}\left(T_{0}\right)=G^{\prime}(T) \quad G_{r}^{\prime \prime} \equiv G^{\prime \prime}\left(T_{0}\right)=G^{\prime \prime}(T) \\
& \eta_{r}^{\prime} \equiv \eta^{\prime}\left(T_{0}\right)=\eta^{\prime}(T) / a_{T} \quad \eta_{r}^{\prime \prime} \equiv \eta^{\prime \prime}\left(T_{0}\right)=\eta^{\prime \prime}(T) / a_{T} \\
& \eta_{r} \equiv \eta\left(T_{0}\right)=\eta(T) / a_{T} \quad \Psi_{1 r} \equiv \Psi_{1}\left(T_{0}\right)=\Psi_{1}(T) / a_{T}^{2}
\end{aligned}
$$

The reduced steady shear viscosity and first normal-stress coefficient data $\left(\eta_{r}, \Psi_{1 r}\right.$ vs. $\left.\dot{\gamma}_{r}\right)$ are plotted in Figures $3 \mathrm{a}$ and $4 \mathrm{a}$ for the PAA100 and PAA300 fluids, respectively. Both figures also include dynamic shear data in appropriate form $\left(\eta_{r}^{\prime}, 2 G_{r}^{\prime} /\right.$ $\omega_{r}^{2}$ vs. $\left.\omega_{r}\right)$ to compare the corresponding limiting behaviors at vanishing deformations, but note their different ordinate scales. The dynamic shear data are plotted separately in Figures $3 \mathrm{~b}$ and $4 \mathrm{~b}$, which include predictions of $G^{\prime}$ and $G^{\prime \prime}$ (solid lines), using a three-mode Maxwell model plus a Newtonian solvent contribution. The parameters of these multimode models are listed in Table 3, at reference temperature $T_{0}$.

The data in Figures $3 \mathrm{a}$ and $4 \mathrm{a}$ clearly show the limiting behavior of the measured properties in steady and dynamic shear flows. The reduced shear viscosity is approximately constant at reduced shear rates in the range 0.3 to $50 \mathrm{~s}^{-1}$ for the PAA100, whereas for the PAA300 it decreases approximately $10 \%$ per decade of reduced shear rate. At $\dot{\gamma}_{r}=54$ and $28 \mathrm{~s}^{-1}$ (for the PAA100 and PAA300, respectively) there is an abrupt growth in $\eta_{r}$ and $\Psi_{1, r}$ and this is accompanied by a slight reduction in reduced shear rate (with the rheometer operating in "controlled stress mode"). This phenomenon results from an elastic instability leading to 3D flow, which is frequently observed with Boger fluids in cone-plate and plate-plate geometries, as investigated previously by Phan-Thien ${ }^{33}$ and McKinley et al. ${ }^{34}$ More details of this instability for these fluids can be found in Alves. ${ }^{30}$

Figures $3 \mathrm{~b}$ and $4 \mathrm{~b}$ show that the three-mode Oldroyd-B model is accurate enough to predict $G^{\prime}$ and $G^{\prime \prime}$ within the measured range, whereas a single-mode model was found to be unable to give accurate predictions of $G^{\prime}$ and $G^{\prime \prime}$ over the whole range of frequencies. Data at low and high frequencies, leading to values of $G^{\prime}$ close to the base line (noise level), were excluded. This baseline, determined as a function of angular speed for deformations of 0.10 and 0.50 using the Newtonian fluids N85 and N91 and deionized water, represents the sensitivity of the rheometer and can be used to estimate the experimental uncertainty in $G^{\prime}$ for the viscoelastic fluids.

The relaxation spectra will be useful later to quantify the

Table 3. Linear Viscoelastic Spectra for Boger Fluids at Reference Temperature $\left(T_{0}=293.15 \mathrm{~K}\right)$

\begin{tabular}{lccc}
\hline & & \multicolumn{2}{c}{$\eta_{k}(\mathrm{~Pa} \cdot \mathrm{s})$} \\
\cline { 3 - 4 } Mode $k$ & $\lambda_{k}(\mathrm{~s})$ & PAA100 & PAA300 \\
\hline 1 & 3.0 & 0.075 & 0.23 \\
2 & 0.3 & 0.027 & 0.090 \\
3 & 0.03 & 0.018 & 0.048 \\
Solvent & - & 0.367 & 0.367 \\
\hline
\end{tabular}




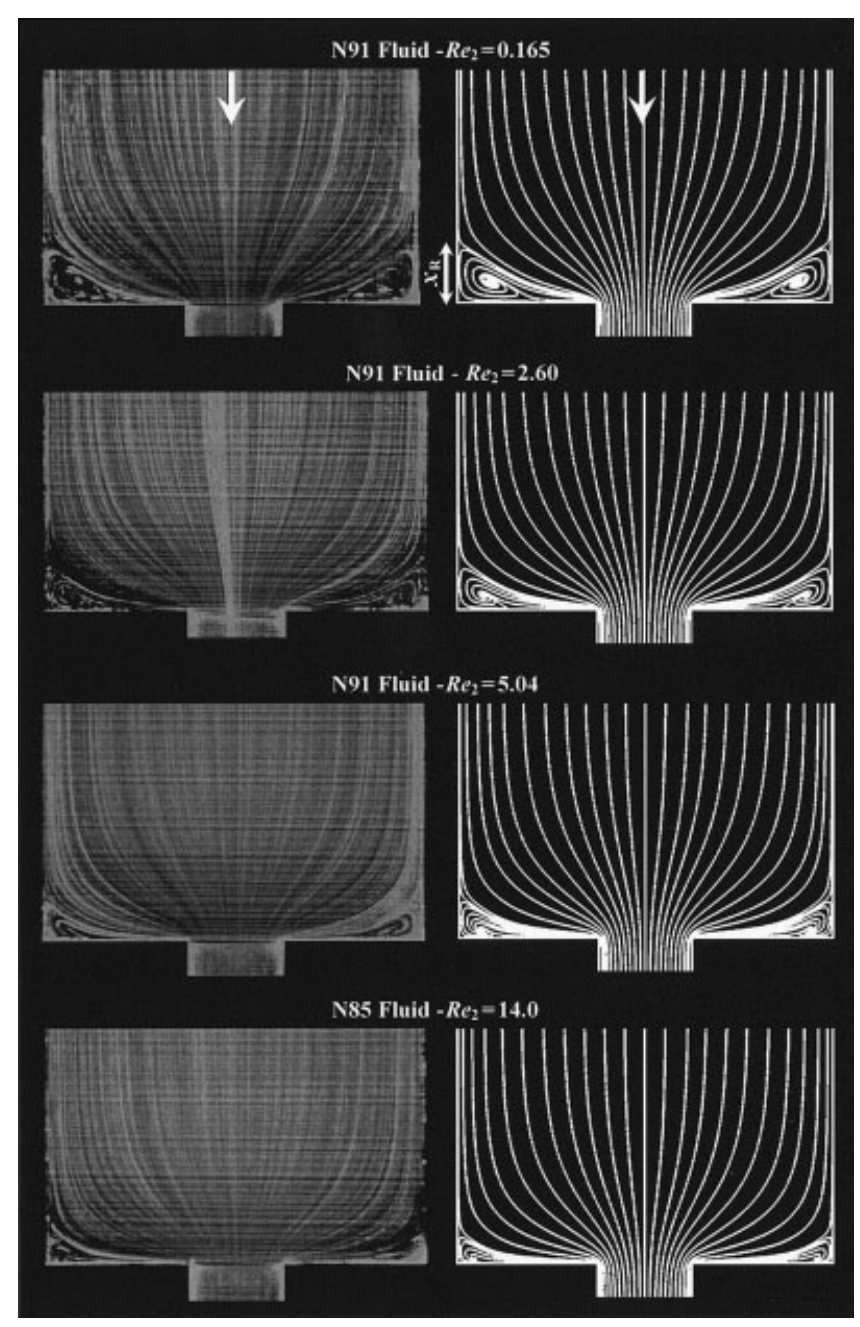

Figure 5. Experimental (left column) and numerical (right column) streaklines for the flow of Newtonian fluids N85 and N91 in the middle plane of a square-square sudden contraction at $T=$ $18.0 \pm 0.2^{\circ} \mathrm{C}$.

Deborah number and for future numerical simulations of this flow. The Deborah number is used here to quantify elastic effects and is defined identically to the Weissenberg number reported in other works in the literature, based on downstream quantities.

\section{Flow Visualization Results}

\section{Newtonian fluids}

Flow visualizations were carried out first with the Newtonian fluids to assess the effect of inertia on the flow structure and to serve as a reference for comparison against the results for the elastic Boger fluids. For the 2-D planar and axisymmetric geometries a fair amount of knowledge has been established on the behavior of Newtonian fluids, ${ }^{10}$ although such information is missing for square-square contractions.

Figure 5 shows photographs of stream traces of the flow of the Newtonian fluids in the middle plane of the 3-D sudden contraction and Figure 6 plots the variation of the normalized vortex length $\left(x_{R} / 2 H_{1}\right)$ with Reynolds number, here defined as

$$
\operatorname{Re}_{2}=\frac{2 \rho H_{2} U_{2}}{\eta}
$$

where $\mathrm{H}_{2}$ and $U_{2}$ designate the downstream duct half-width and bulk velocity, respectively.

As expected, inertia leads to a reduction of the corner vortex, especially noticeable for Reynolds numbers $>1$. At low Reynolds numbers, inertial effects are negligible and $x_{R} / 2 H_{1}$ asymptotes to 0.163 . It is interesting to note that, under creeping flow conditions, the vortex size for a 4:1 circular contraction asymptotes to exactly the same value, $x_{R} / 2 H_{1} \rightarrow 0.163$, whereas for a 4:1 2-D planar contraction the size is somewhat different, $x_{R} / 2 H_{1} \rightarrow 0.1875$ (values based on numerical simulations; see Alves et al. $\left.{ }^{30,35}\right)$. For the circular contraction, Boger ${ }^{10}$ quotes a value of $x_{R} /\left(2 H_{1}\right)=0.17 \pm 0.01$ based on both experiments and numerical predictions, in close agreement with our simulations.

For Newtonian fluids, all the experimental flow features are well captured by numerical simulations, shown on the right column of Figure 5; in addition, the predicted variation of the vortex length with the Reynolds number, shown by the curve in Figure 6, quantitatively matches the measured data. These numerical simulations were obtained with a finite-volume methodology developed by the authors. ${ }^{36}$

Figure 5 also highlights the point that, even though at first sight the flow inside the vortex looks $2-\mathrm{D}$, in reality it is 3-D. In contrast with the planar and axisymmetric sudden contraction flows, none of the recirculations is ever closed in the square contraction, as revealed by a careful inspection of the streaklines. This was also confirmed by visual inspection and especially by the numerical calculations from which the flow description sketched in Figure 7 was outlined. Figure 7 shows streaklines from fluid particles starting at two different planes in the upstream duct: the middle plane perpendicular to the wall (ABCD), always seen in the photos, and the second plane (EFGH) at $45^{\circ}$ to the wall passing through opposite corners of the square cross section (hereafter referred to as corner plane).

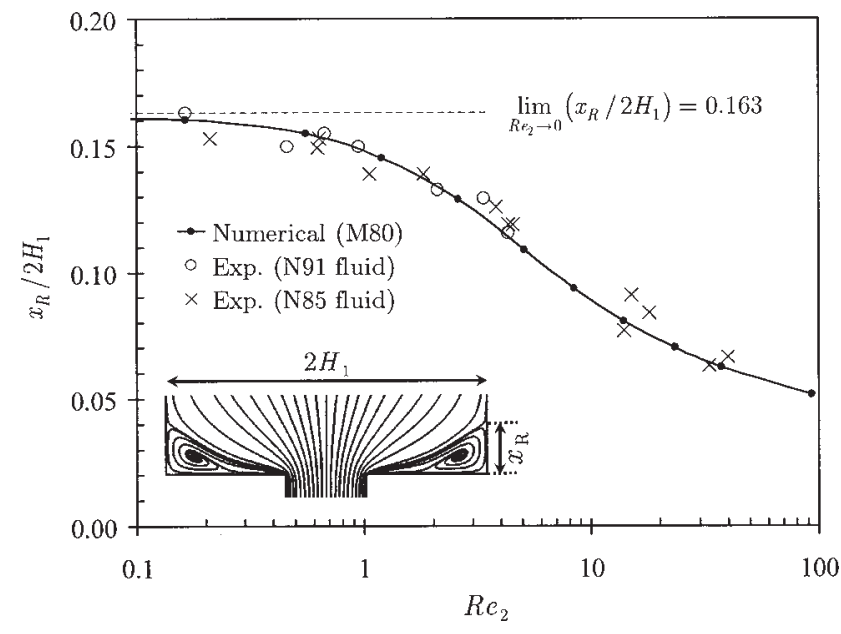

Figure 6. Influence of the Reynolds number on the vortex length at the middle plane of a squaresquare sudden contraction for Newtonian fluids N85 and N91.

Comparison between experiments and numerical predictions. 


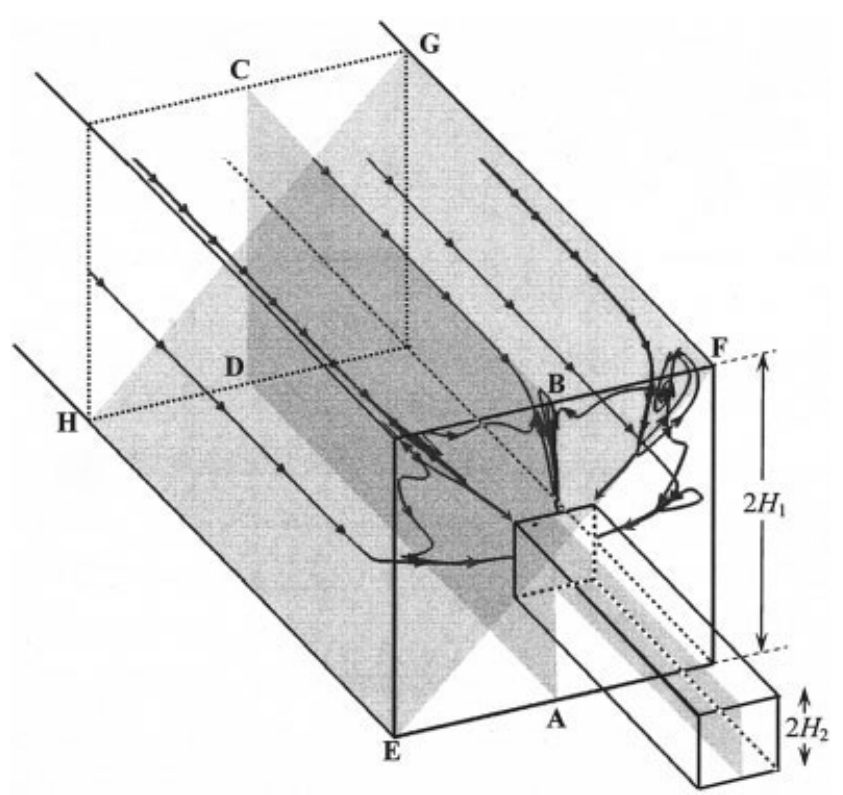

Figure 7. 3-D particle trajectories for a Newtonian fluid under conditions of negligible inertia.

Particles flowing near the walls along the corner plane enter the corner-plane vortex, rotate toward its center, and then drift toward the middle plane along the eye of the recirculating region, in this way entering the vortex located at the middle plane. Once here the particles now rotate toward the periphery of the middle-plane vortex and exit the vortex at the reentrant corner going into the downstream duct.

Open 3-D recirculations were also predicted by other authors who simulated Newtonian flows in 3-D sudden expansions ${ }^{37,38}$ (quasi-2-D as the expansion took place in one dimension only) and in 3-D (quasi-2-D) backward-facing steps. ${ }^{39,40}$ The inhomogeneous flow conditions experienced by fluid particles coming either along the upstream square-duct walls or along its corners, into the contraction plane region, result in different velocity gradients, thus leading to stress gradients and complex secondary flows.

\section{Boger fluids}

To quantify the strength of elastic effects with Boger fluids it is convenient to use a single relaxation time in the definition of the Deborah number, which can be either based on upstream $\left(\mathrm{De}_{1}\right)$ or downstream flow conditions $\left(\mathrm{De}_{2}\right)$. Most studies of contraction flows define the Deborah number with a deformation rate characteristic of downstream flow conditions (leading to $\mathrm{De}_{2}$ ). Alves et al. ${ }^{41}$ showed that lip vortex activity (when present) scales with $\mathrm{De}_{2}$, independently of the contraction ratio $(\beta)$, whereas dimensionless corner vortex size $\left(x_{R} / 2 H_{1}\right)$ and intensity depend on $\mathrm{De}_{2} / \beta$. Thus, hereafter the results are presented with Deborah number based on downstream quantities, $\mathrm{De}_{2}$. Nevertheless, conversion between upstream and downstream Reynolds and Deborah numbers is straightforward: $\operatorname{Re}_{2}=4 \mathrm{Re}_{1} ; \mathrm{De}_{2}=64 \mathrm{De}_{1}$.

The downstream Deborah number is defined as

$$
\mathrm{De}_{2}=\frac{\lambda_{p}(T) U_{2}}{H_{2}}=\frac{a_{T} \lambda_{p}\left(T_{0}\right) U_{2}}{H_{2}}
$$

where $\lambda_{p}$ is an equivalent relaxation time based on the Oldroyd-B model, and calculated from the linear viscoelastic spectra using the following equations

$$
\begin{gathered}
\eta_{p}=\sum_{k \neq \text { solvent }} \eta_{k} \\
\lambda_{p}=\frac{1}{\eta_{p}} \sum_{k \neq \text { solvent }} \eta_{k} \lambda_{k}
\end{gathered}
$$

In this way, it is guaranteed that at low deformation rates (and low angular velocities), the viscoelastic behavior of the equivalent single mode Oldroyd-B model is identical to that of the multimode model (say, $\Psi_{1,0} \equiv \lim _{\dot{\gamma} \rightarrow 0} \Psi_{1}=\sum_{\mathrm{k}} 2 \eta_{k} \lambda_{k}=$ $2 \eta_{p} \lambda_{p}$ ). This definition of relaxation time considers only the role of the polymer additive in the absence of solvent to establish the elasticity of the fluid, but it should be noted that some authors prefer to define a Maxwell relaxation time as $\lambda_{0}$ $=\Psi_{1,0} / 2 \eta_{0}$

Thus, from the data in Table 3 the parameters of the equivalent single-mode Oldroyd-B model are the following: for the PAA100, $\eta_{0} \equiv \eta_{s}+\eta_{p}=0.487 \mathrm{~Pa} \cdot \mathrm{s}$, resulting in a solvent viscosity ratio $\eta_{s} / \eta_{0}=0.754$, and a relaxation time $\lambda_{p}=1.947$ $\mathrm{s}$; for the PAA300, $\eta_{0} \equiv \eta_{s}+\eta_{p}=0.735 \mathrm{~Pa} \cdot \mathrm{s}, \eta_{s} / \eta_{0}=0.499$, and $\lambda_{p}=1.952 \mathrm{~s}$. Clearly, with the relaxation time defined as in Eq. 8 we have almost the same relaxation time for both Boger fluids. Because these two polymer solutions are dilute, the configurations/behavior of the individual polymer molecules in the same solvent should not differ significantly, and so the relaxation times of the molecules should be similar. However, a higher polymer concentration leads to higher "elasticity" because the fluid becomes more viscous and the polymer molecules take longer to relax. This can be quantified in two alternative ways, either by using the total viscosity of the fluid to calculate the Maxwell relaxation time, as mentioned above (leading to $\lambda_{0}=0.480$ and $0.977 \mathrm{~s}$ for PAA100 and PAA300, respectively), or by using the so-called elasticity number $\left(\mathrm{El}_{2}\right)$, defined by the ratio of the Deborah and Reynolds numbers

$$
E l_{2}=\frac{\mathrm{De}_{2}}{\mathrm{Re}_{2}}=\frac{\lambda_{p} \eta_{0}}{2 \rho H_{2}^{2}}
$$

which is independent of flow kinematics and takes into account the viscosity of the solution: $E l_{2}=42.2$ and 63.9 for the PAA100 and PAA300, respectively. This results in the PAA300 fluid being 1.52 times more elastic than PAA100. We note, however, that if the elasticity number is defined as $E l=$ $\lambda_{p} \eta_{p} / 2 \rho H_{2}^{2}\left(=\Psi_{1,0} / 4 \rho H_{2}^{2}\right)$, to be consistent with the definition of $\lambda_{p}$, then the PAA300 fluid is approximately three times more "elastic" than PAA100 (in agreement with the ratio between the zero shear rate values of the first normal stress coefficient measured for both fluids), a figure more in line with the increase in polymer concentration. In any case, whatever the definition adopted to measure "elasticity," the solution of PAA300 is more elastic than that of PAA100 and this effect explains the different flow behaviors reported hereafter.

Streak photographies at the middle plane of the contraction are presented in Figure 8 for the flow of the PAA100 fluid for increasing values of the flow rate. The flow characteristics are 


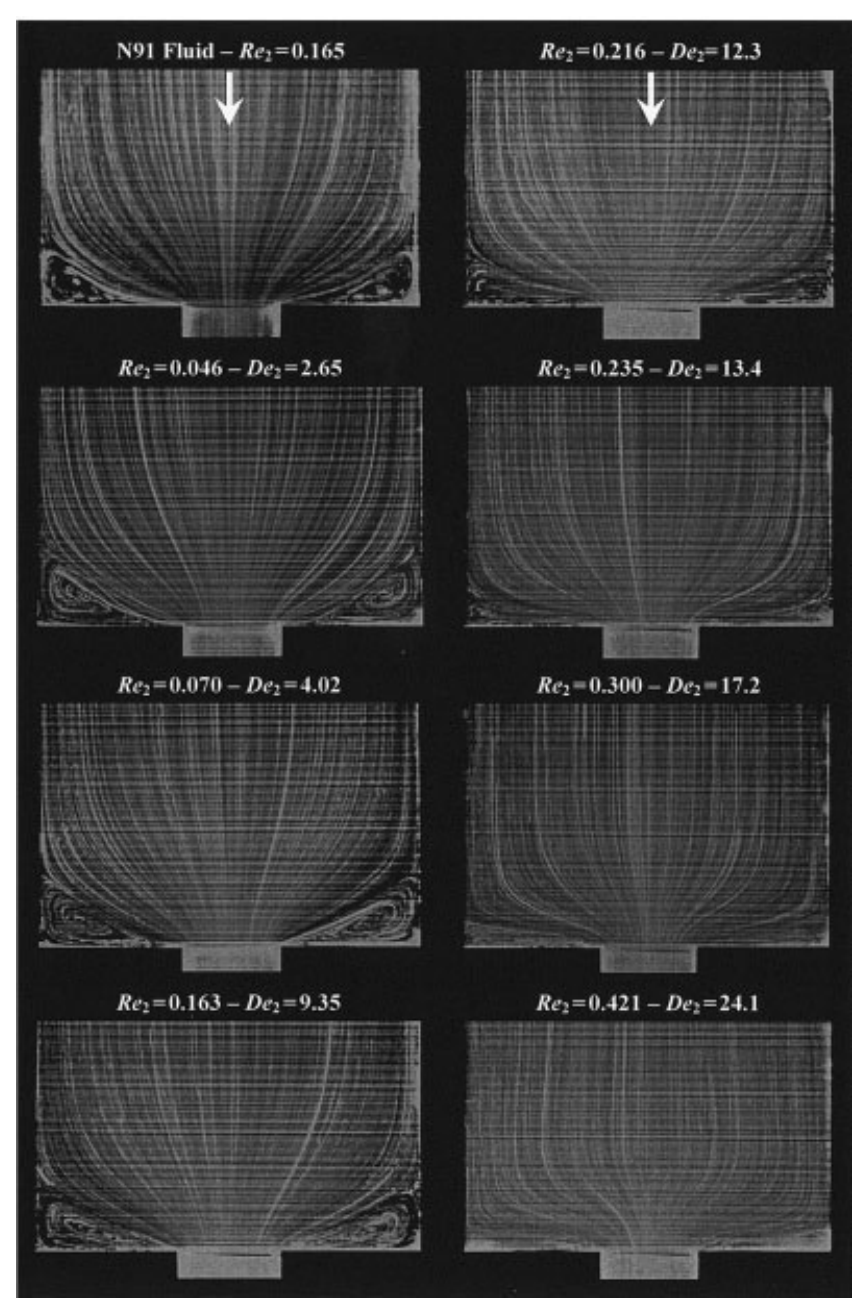

Figure 8. Influence of elasticity on the streakline flow patterns at the middle plane of a $4: 1$ squaresquare sudden contraction for PAA100 at $T=$ $18.1 \pm 0.2^{\circ} \mathrm{C}$.

complex, but are caused only by elastic effects because inertia is not significant $\left(\mathrm{Re}_{2}<0.95\right)$. At relatively low values of the Deborah number $\left(\mathrm{De}_{2}=2.65\right)$, viscous effects predominate and the flow pattern is similar to that seen in Figure 5 for Newtonian fluids, with a concave separation streakline and the 3 -D nature of the recirculating flow in evidence. With increasing Deborah number changes progressively occur: first, there is a very slight increase in vortex size while the separation streakline straightens; then, the corner vortex progressively decreases in size to about a quarter at $\mathrm{De}_{2} \cong 15$, an effect that cannot be attributed to inertia because the Reynolds number remains well below $\mathrm{Re}_{2}=1$. McKinley et al. ${ }^{8}$ reported results in the $4: 1$ axisymmetric contraction bearing some resemblance with these: negligible elastic effects for $\operatorname{De}_{2}(\dot{\gamma})<1$ (using a shearrate-dependent Maxwell relaxation time) and a decrease in the corner vortex size for Deborah numbers up to $\operatorname{De}_{2}(\dot{\gamma}) \approx 3$. However, in contrast to McKinley et al. for the axisymmetric contraction, the formation of a strong lip vortex while the corner vortex decreases in size is not seen in the present experiments, although the higher curvature of the streaklines at the reentrant corner suggests the possibility that a weak lip

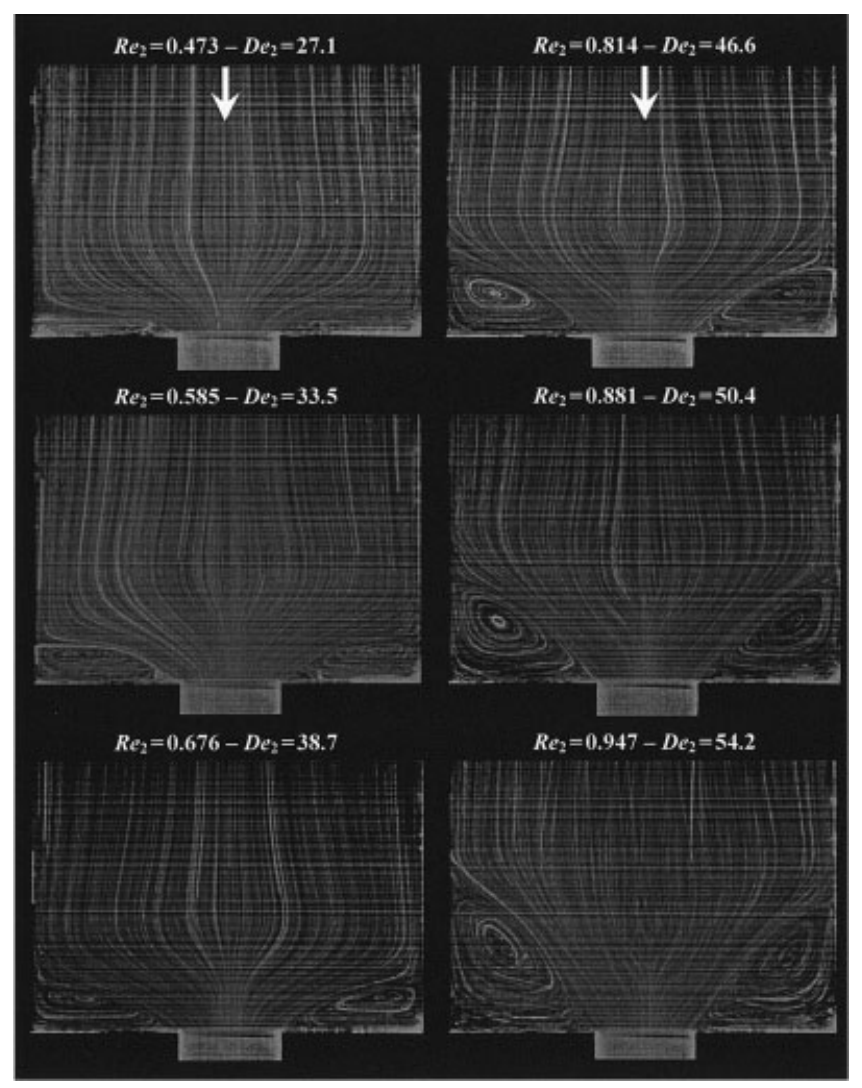

vortex does exist (see photo for $\mathrm{De}_{2}=13.4$ ). In fact, the decrease of $x_{R}$ at low $\mathrm{De}_{2}$ is compatible with the existence of a lip vortex, ${ }^{19}$ although it has been observed that $x_{R}$ usually grows monotonically when such a lip vortex is absent. In addition, the fluids used in those references were clearly more elastic than here: in McKinley et al. ${ }^{8}$ the elasticity number is evaluated as $E l_{2} \approx 610$ and in Rothstein and McKinley ${ }^{12}$ as $E l_{2}$ $\approx 2100$.

As the Deborah number further increases the corner vortex starts to grow, and simultaneously there are changes in the characteristics of the streamlines approaching the contraction plane. For $\mathrm{De}_{2} \geq 24.1$, the approach flow streaklines in the middle plane and close to the contraction are seen to progressively diverge with flow elasticity, moving away from the centerline. This anomalous effect had already been predicted by Oliveira and Pinho ${ }^{42,43}$ and Alves et al. ${ }^{18}$ for the flow of Boger fluids in a 4:1 plane sudden contraction and was also observed in the experiments of McKinley et al. ${ }^{8}$ for the flow of a Boger fluid in circular contractions. Attempts to explain the causes for divergence of streamlines upstream of the contraction for Boger fluids have pointed to a local intense increase in extensional viscosity leading to an increased flow resistance in the centerline just upstream of the contraction plane as the extension rates grow in a region of predominantly extensional flow characteristics. Such extensional thickening is a characteristic of Boger fluids, but there are not enough data to correlate rheological behavior with diverging flow. McKinley et al. ${ }^{8}$ discuss this issue and mention different degrees of flow divergence for fluids with similar extensional viscosity behavior, arguing for the relevance of the total Hencky strain to this 
flow feature. However, the total Hencky strain is here unchanged because it is a function of the contraction ratio. Also of note here, the diverging streamlines with Boger fluids were observed in the absence of noticeable lip vortex activity. This contrasts with the visualizations of McKinley et al. ${ }^{8}$ in the axisymmetric geometry, but agrees with their conclusions that diverging streamlines and lip vortex formation are probably unrelated.

As discussed more recently by Rothstein and McKinley, ${ }^{12}$ extensional viscosity alone does not explain the variety of flow features in contraction flows; hysteresis effects on the stressconformation, normal stress effects in shear and extension, as well as contraction ratio and transient extensional viscosity behavior are relevant to the existence or not of a lip vortex and to the enhanced pressure drop, so the issue of diverging streamlines should be at least as complex. In fact, the early experiments of Cable and Boger-6 had already shown strong diverging flow in the presence of combined shear-thinning and inertial effects, suggesting that inhomogeneous shear conditions near the wall are equally important. Quite interestingly, in the experiments of Walters and Rawlinson ${ }^{24}$ in a 13.3:1 square-square contraction, there is an abrupt expansion of the central jet as the fluid is just about to enter the smaller duct (cf. their Figure 5 at $W=0.002$ ), but there is already an enhanced vortex and the diverging streamlines may be related in part to the fluid particles being dragged into the recirculation, something that we did not observe in our experiments.

The growth of the large vortex continues with elasticity, and the flow remains steady up to $\mathrm{De}_{2} \approx 52$. At higher Deborah numbers, the 3-D nature of the recirculating flow seems to have changed, as can be assessed by careful comparison of streaklines in the recirculation at $\mathrm{De}_{2}=50.4$ with those taken at low Deborah numbers. As the Deborah number further increases the flow becomes periodic, possibly because of an elastic instability, and this is observed by the crossings in some streaklines at $\mathrm{De}_{2}=54.2$. The amplitude of the oscillations increases with $\mathrm{De}_{2}$, as seen in the three photos of Figure 9 taken at three moments in time within a cycle for two different supercritical flow conditions. At even higher flow rates the flow loses its periodicity.

For the more concentrated Boger fluid, PAA300, the streakline flow visualizations are shown in Figures 10a and 10b for conditions corresponding to two different temperatures, $T=$ 21.0 and $17.5^{\circ} \mathrm{C}$. The second set was taken 3 months after the first, with the same fluid sample (it was stored in a refrigerator), and with the purpose of checking the repeatability of the flow and absence of fluid degradation over time under the tested conditions. In general terms, the influence of Deborah number is the same as for PAA100, but a couple of important differences are worth mentioning. First, the increase of the corner vortex located on the axial midplane at low Deborah numbers is also observed, but it is now more intense than that with the PAA100 fluid. This is clear in Figure 11, which compares the variation for both fluids of the vortex size in the midplane against the Deborah number $\left(\mathrm{De}_{2}\right)$ : for PAA300 $x_{R} / 2 H_{1}$ peaks by more than $25 \%$ relative to the Newtonian value at $\mathrm{De}_{2} \approx 6$, followed by a decrease to about 0.07 in the range $\mathrm{De}_{2}=6$ to 15. A second more important difference in relation to PAA100 is that a lip vortex is now clearly seen in the midplane for a certain range of Deborah numbers (see photos at $\mathrm{De}_{2}=8.70$ and 9.62 in Figure 10). In particular, at $\mathrm{De}_{2}=9.62$ when

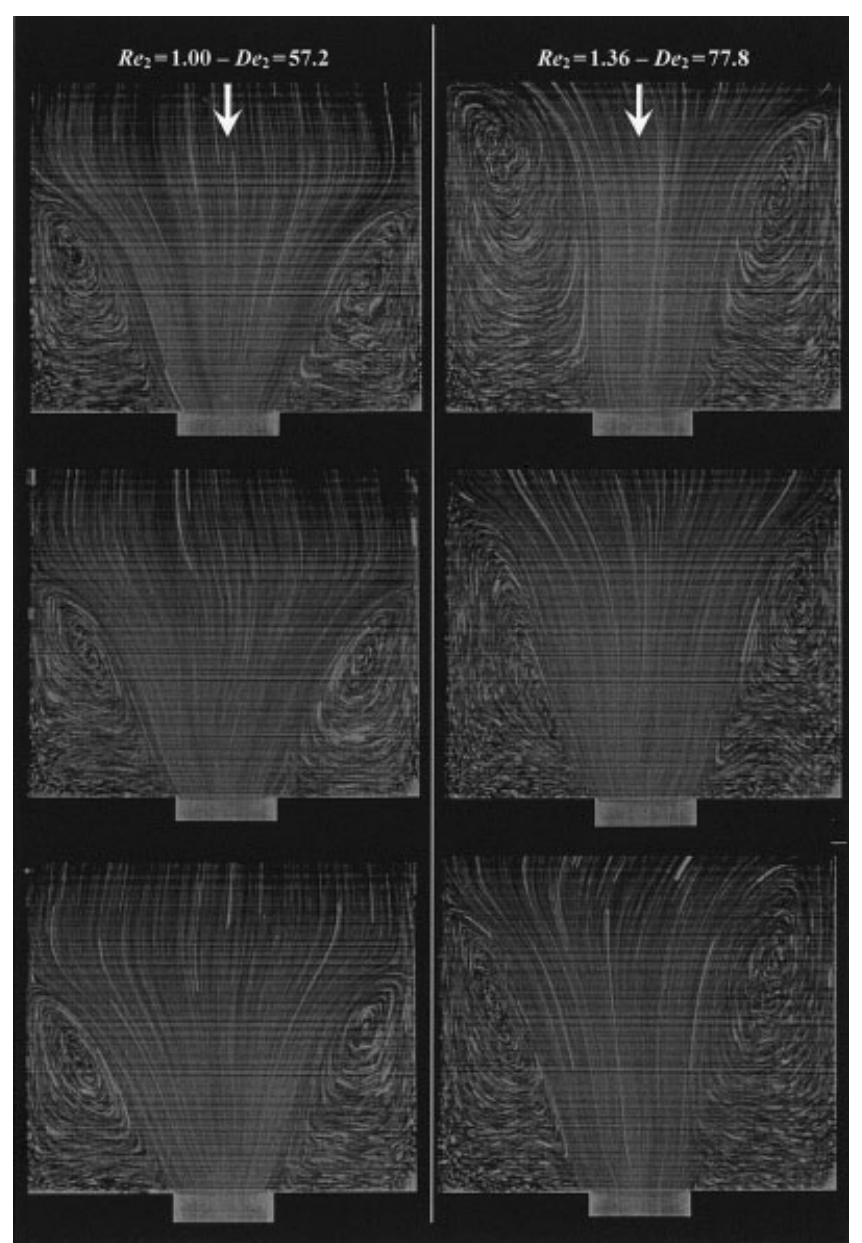

Figure 9. Streaklines for the flow of PAA100 in the middle plane of a square-square contraction at three different moments within two different oscillating supercritical flow conditions.

inertia is still negligible, the lip vortex has similarities to that found for Boger fluids in the 4:1 plane contraction calculations of Alves et al. ${ }^{18}$ (cf. their Figure 7 at $\mathrm{De}_{2}=4$ for UCM fluids).

It is known from experimental and numerical work in the 4:1 plane sudden contraction flow with Boger fluids, ${ }^{23,44}$ that a lip vortex is formed at low to moderate Deborah numbers. This lip vortex grows with elasticity and eventually dominates the corner vortex, the characteristic flow feature of Newtonian flows and low-Deborah number viscoelastic flows. In contrast, for the axisymmetric sudden contraction flow of Boger fluids the corner vortex is normally found to grow with elasticity without the presence of any lip vortex ${ }^{35,45}$; there are exceptions to this Boger fluid behavior, as in the experiments of Boger et al. ${ }^{9}$ and McKinley et al. ${ }^{8}$ with PIB/PB solutions. Boger and Binnington $^{46}$ also observed a lip vortex mechanism for a PAAbased fluid in a 4:1 circular contraction with rounded corners, in deep contrast with the (usual) strong corner vortex enhancement observed in the same 4:1 circular contraction, but with a sharp reentrant corner. Rothstein and McKinley ${ }^{12}$ argued about the competing roles of extensional stresses and shear-induced normal stresses on vortex growth mechanisms, and concluded that lip vortices are associated with a domination of shear- 

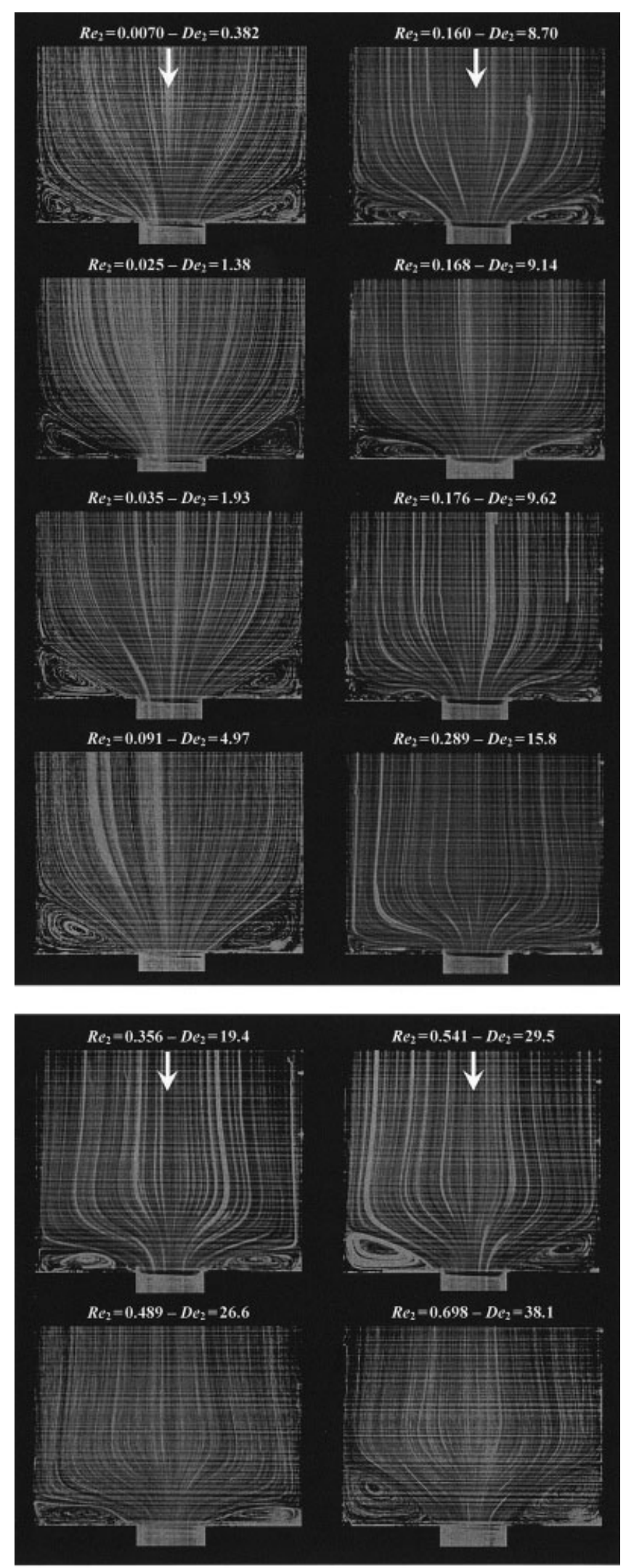

(a)

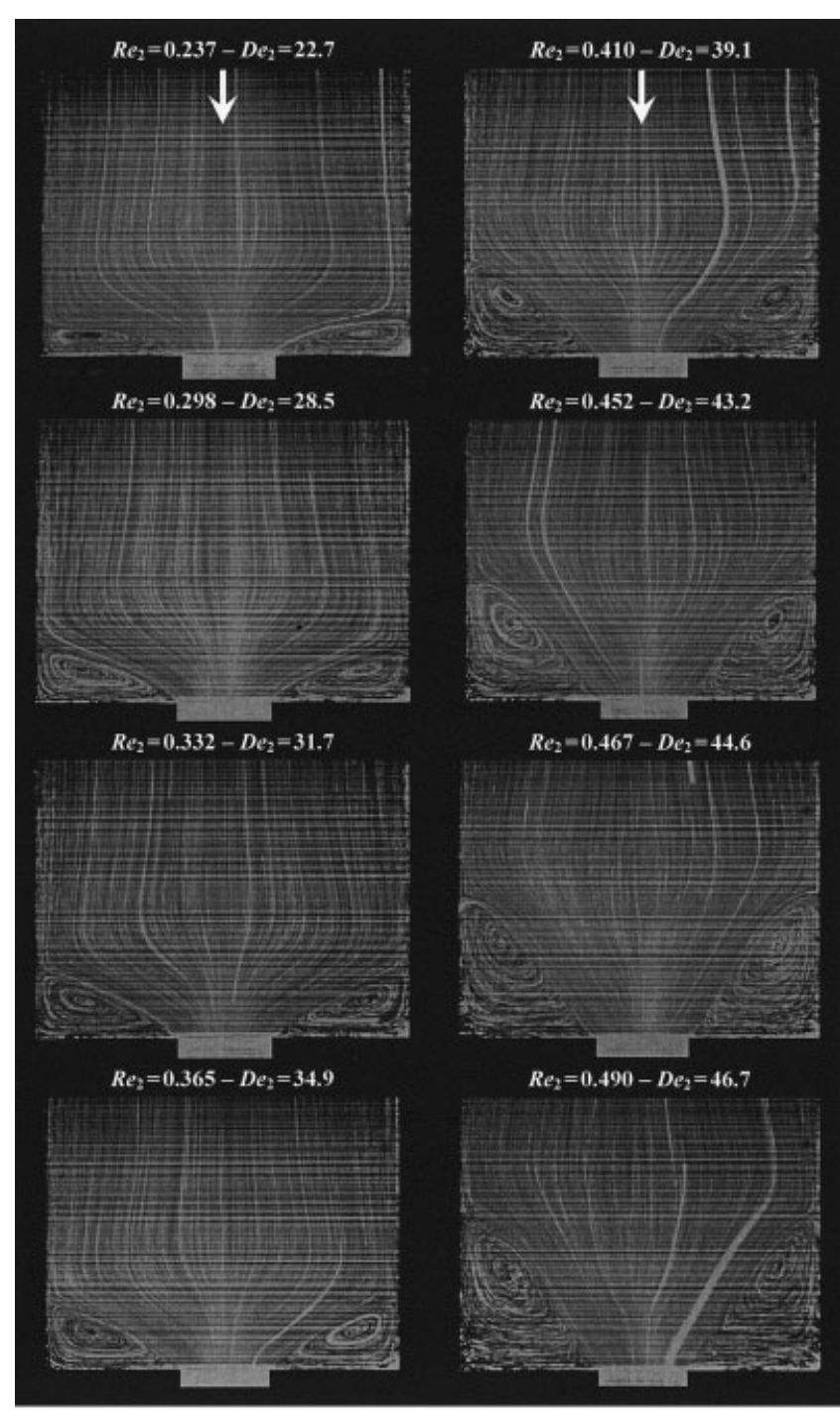

(b)

Figure 10. Influence of elasticity on the streakline flow patterns at the middle plane of a 4:1 squaresquare sudden contraction for PAA300.

(a) Visualizations at $21.0^{\circ} \mathrm{C}$; (b) visualizations at $17.5^{\circ} \mathrm{C}$.

induced elasticity, whereas corner vortex growth is dominated by extensional stresses, thus predominating at large contraction ratios and/or large Deborah numbers.

Given the similarities between the square-square contraction and the axisymmetric geometry in terms of both extensional strain rates developed along the centerline and the possibility of partial balance of cross-stream/azimuthal pressure and stress gradients, it comes as no surprise that the visualizations of Evans and Walters ${ }^{16}$ for a square-square 16:1 contraction do not show any lip vortex and instead illustrate a strong enhancement of the middle plane corner vortex (see their Figure 11) The presence of cross-stream secondary flows in the square contraction increases shear-induced normal stresses relative to those found in the corresponding circular contraction flow and, according to the above mechanism of Rothstein and McKinley, this will widen the range of contraction ratios where the lip 


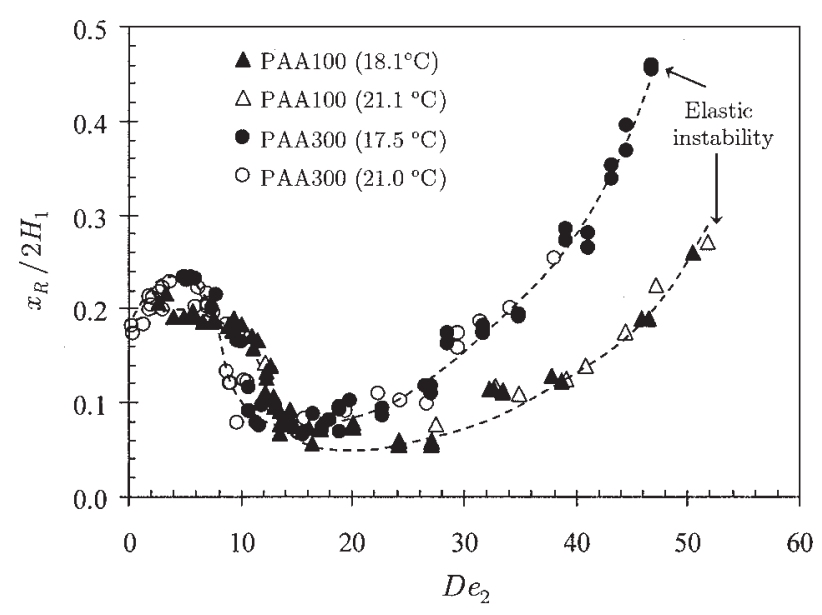

Figure 11. Variation of normalized vortex length with flow elasticity for Boger fluids PAA100 and PAA300.

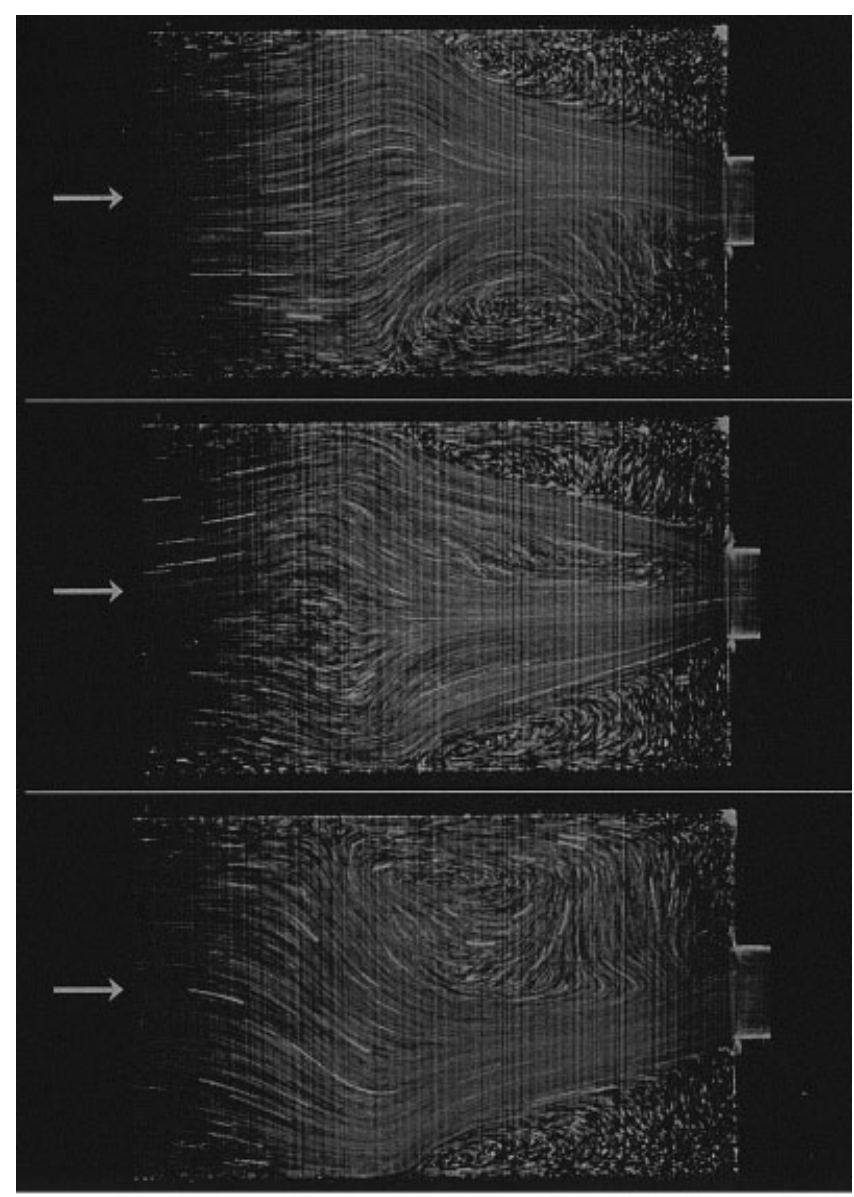

(a)

Figure 12. Streaklines for the flow of PAA300 in the middle plane of a square-square contraction at three different moments within oscillating supercritical flow conditions.

(a) $\mathrm{De}_{2}=55.1$ and $\mathrm{Re}_{2}=0.577$; (b) $\mathrm{De}_{2}=61.5$ and $\mathrm{Re}_{2}=$ 0.643 . vortex is observed. Such an effect is similar to rounding the reentrant corner in axisymmetric contractions: Rothstein and McKinley ${ }^{12}$ report for this case the existence of a lip vortex for the $4: 1$ contraction and a delay in corner vortex development, confirming the observations of Boger and Binnington. ${ }^{46}$

At higher flow rates/elasticity $\left(\mathrm{De}_{2}>20\right)$ there is vortex enhancement through a lip vortex mechanism. A diverging streakline pattern upstream of the contraction plane is also observed, but now in the presence of a lip vortex. The appearance of diverging streaklines in a 3-D square-square contraction flow of Boger fluids, with and without lip vortex, is documented here for the first time and confirms the suggestion of McKinley et al. ${ }^{8}$ that the two phenomena are probably unrelated. Simulations by Oliveira and Pinho ${ }^{42}$ for creeping flow of UCM fluid in a 4:1 planar contraction corroborate this point, and the numerical results presented in Oliveira and Pinho $^{43}$ for the same flow under conditions where inertia is not negligible $\left(\operatorname{Re}_{2}=1\right)$ illustrate that inertial effects enhance streamline divergence for high Deborah number flows.

At even higher Deborah numbers, say for $\mathrm{De}_{2} \geq 46.7$ (De $_{1}$ $\geq 0.726$ ), the flow of PAA300 becomes periodic, showing a behavior similar to that reported above for the PAA100 fluid. This periodic flow results from an elastic instability and occurs earlier than for the PAA100 solution, at $\mathrm{De}_{2} \cong 45\left(\mathrm{De}_{1} \cong 0.7\right)$. Figure 12 shows three photos with the PAA300 solution pertaining to a cycle of events for two different supercritical flow

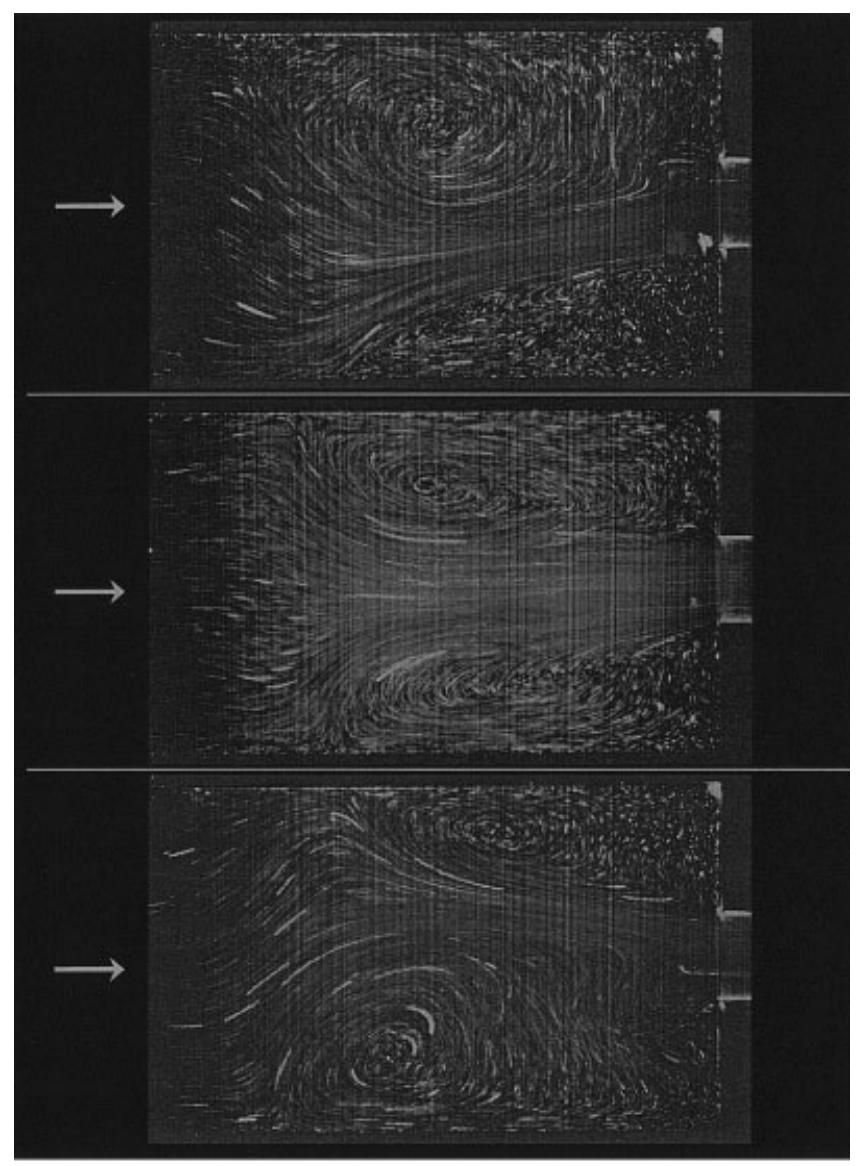

(b) 
conditions, confirming that the time-average size of the timedependent vortex continues to grow with Deborah number.

\section{Conclusions}

Flow visualizations were carried out in the middle plane of a 4:1 square-square sudden contraction for Newtonian and Boger fluids under conditions of negligible inertia, using streakline photography. The Newtonian flow patterns were in good agreement with our own numerical results and show inertia to be negligible for Reynolds numbers below $\mathrm{Re}_{2} \approx 1$. The flow field was clearly three-dimensional, exhibiting open vortices with both Newtonian and viscoelastic fluids, and inertia tended to push the corner vortex toward the contraction plane.

For the two Boger fluids the upstream vortices were seen to increase slightly at low Deborah numbers, before an intense decrease took place leading to a minimum vortex size at $\mathrm{De}_{2} \approx$ 15. As the Deborah number further increased, the streaklines on the central region of the approaching flow started to diverge, whereas the vortices grew strongly with elasticity until the flow became periodic and eventually chaotic at higher flow rates.

For the more concentrated Boger fluid (PAA300) these effects were more intense because of the corresponding higher elasticity number, and a major difference in flow features was clearly seen: after the vortex attained its minimum size at intermediate Deborah numbers, $10 \leq \mathrm{De}_{2} \leq 15$, a lip vortex appeared and grew with elasticity. For the PAA100 solution, and although only corner vortex enhancement was observed, the variation of vortex size with Deborah number was compatible with the existence of a weak lip vortex (not captured with our visualization technique).

We speculate that the secondary flow in the cross section of the rectangular channel tends to increase the role of shearinduced normal stresses, thus leading to the appearance of a lip vortex at this contraction ratio and consequently delaying the vortex growth and instability to higher Deborah numbers, compared to the corresponding situation of a circular contraction. Such flow features, and the existence of a diverging flow well upstream of the contraction, are reported here for the first time in relation to the square-square contraction flow of Boger fluids. However, similar flow features have been previously reported for circular contractions.

\section{Acknowledgments}

The authors thank Prof. M. P. Gonçalves and D. Torres for help in characterizing the rheology of the fluids used in this work. M. A. Alves thanks Fundação Calouste Gulbenkian for financial support. Sponsorship of FEDER by the FCT program POCTI/EME/37711/2001 is gratefully acknowledged. Finally we are grateful for the relevant comments of one of the reviewers whose helpful suggestions significantly improved this article.

\section{Literature Cited}

1. Van Dyke M. An Album of Fluid Motion. Stanford, CA: The Parabolic Press; 1982.

2. Boger DV, Walters K. Rheological Phenomena in Focus. Amsterdam: Elsevier; 1993.

3. Hassager O. Working group on numerical techniques. Fifth International Workshop on Numerical Methods in Non-Newtonian Flows, Lake Arrowhead, USA. J Non-Newt Fluid Mech. 1988;29:2-5.

4. Cable PJ, Boger DV. A comprehensive experimental investigation of tubular entry flow of viscoelastic fluids: Part I. Vortex characteristics in stable flow. AIChE J. 1978;24:868-879.
5. Cable PJ, Boger DV. A comprehensive experimental investigation of tubular entry flow of viscoelastic fluids: Part II. The velocity fields in stable flow. AIChE J. 1978;24:992-999.

6. Cable PJ, Boger DV. A comprehensive experimental investigation of tubular entry flow of viscoelastic fluids: Part III. Unstable flow. AIChE J. 1979;25:152-159.

7. Nguyen H, Boger DV. The kinematics and stability of die entry flows. J Non-Newt Fluid Mech. 1979;5:353-368.

8. McKinley GH, Raiford WP, Brown RA, Armstrong RC. Non linear dynamics of viscoelastic flow in axisymmetric abrupt contractions. $J$ Fluid Mech. 1991;223:411-456.

9. Boger DV, Hur DU, Binnington RJ. Further observations of elastic effects in tubular entry flows. J Non-Newt Fluid Mech. 1986;20:31-49.

10. Boger DV. Viscoelastic flows through contractions. Ann Rev Fluid Mech. 1987; 19:157-182.

11. Rothstein JP, McKinley GH. Extensional flow of a polystyrene Boger fluid through a 4:1:4 axisymmetric contraction/expansion. J Non-Newt Fluid Mech. 1999;86:61-88.

12. Rothstein JP, McKinley GH. The axisymmetric contraction-expansion: The role of extensional rheology on vortex growth dynamics and the enhanced pressure drop. J Non-Newt Fluid Mech. 2001;98:33-63.

13. Phillips SD, Joo YL, Brown RA, Armstrong RC. Modeling and simulation of the flow through an axisymmetric contraction-expansion using a multi-mode Adaptive Length Scale model, Paper NF25, Proc of the XIV International Congress on Rheology (in CD-ROM), Seoul, Korea; 2004.

14. Ghosh I, Joo YL, McKinley GH, Brown RA, Armstrong RC. A new model for dilute polymer solutions in flows with strong extensional components. J Rheol. 2002;46:1057-1089.

15. Walters K, Webster MF. On dominating elastico-viscous response in some complex flows. Philos Trans R Soc Lond A Phys Sci. 1982;308: 199-218.

16. Evans RE, Walters K. Flow characteristics associated with abrupt changes in geometry in the case of highly elastic liquids. J Non-Newt Fluid Mech. 1986;20:11-29.

17. Evans RE, Walters K. Further remarks on the lip-vortex mechanism of vortex enhancement in planar contraction flows. J Non-Newt Fluid Mech. 1989;32:95-105.

18. Alves MA, Pinho FT, Oliveira PJ. Effect of a high-resolution differencing scheme on finite-volume predictions of viscoelastic flows. $J$ Non-Newt Fluid Mech. 2000;93:287-314.

19. Alves MA, Oliveira PJ, Pinho FT. Benchmark solutions for the flow of Oldroyd-B and PTT fluids in planar contractions. J Non-Newt Fluid Mech. 2003;110:45-75.

20. White SA, Baird DG. The importance of extensional flow properties on planar entry flow patterns of polymer melts. J Non-Newt Fluid Mech. 1986;20:93-101.

21. White SA, Baird DG. Flow visualization and birefringence studies on planar entry flow behaviour of polymer melts. J Non-Newt Fluid Mech. 1988;29:245-267.

22. White SA, Baird DG. Numerical simulation studies of the planar entry flow of polymer melts. J Non-Newt Fluid Mech. 1988;30:47-71.

23. Nigen S, Walters K. Viscoelastic contraction flows: Comparison of axisymmetric and planar configurations. J Non-Newt Fluid Mech. 2002; 102:343-359.

24. Walters K, Rawlinson DM. On some contraction flows for Boger fluids. Rheol Acta. 1982;21:547-552.

25. Xue SC, Phan-Thien N, Tanner RI. Numerical investigations of Lagrangian unsteady extensional flows of viscoelastic fluids in 3-D rectangular ducts with sudden contractions. Rheol Acta. 1998;37:158169.

26. Mompean G, Deville M. Unsteady finite volume simulation of Oldroyd-B fluid through a three-dimensional planar contraction. J NonNewt Fluid Mech. 1997;72:253-279.

27. Xue SC, Phan-Thien N, Tanner RI. Three dimensional numerical simulations of viscoelastic flows through planar contractions. $J$ NonNewt Fluid Mech. 1998;74:195-245.

28. Stokes JR. Swirling Flow of Viscoelastic Fluids. PhD Dissertation. Melbourne, Australia: Dept. of Chemical Engineering, University of Melbourne; 1998.

29. Barnes HA. A Handbook of Elementary Rheology. Aberystwyth, Wales: Institute of Non-Newtonian Fluid Mechanics, University of Wales; 2000.

30. Alves MA. Laminar Flow of Viscoelastic Fluids: Numerical, Theoret- 
ical and Experimental Analysis (in Portuguese). PhD Dissertation. Porto, Portugal: Dept. of Chemical Engineering, University of Porto; 2004.

31. Bird RB, Armstrong RC, Hassager O. Dynamics of Polymeric Liquids. Volume 1: Fluid Dynamics. New York, NY: Wiley; 1987.

32. Quinzani LM, McKinley GH, Brown RA, Armstrong RC. Modeling the rheology of polyisobutylene solutions. J Rheol. 1990;34:705-748.

33. Phan-Thien N. Cone-and-plate flow of the Oldroyd-B fluid is unstable. J Non-Newt Fluid Mech. 1985;17:37-44.

34. McKinley GH, Byars JA, Brown RA, Armstrong RC. Observations on the elastic instability in cone-and-plate and parallel-plate flows of a polyisobutylene Boger fluid. J Non-Newt Fluid Mech. 1991;40:201229.

35. Alves MA, Oliveira PJ, Pinho FT. Numerical simulation of viscoelastic contraction flows. In: Bathe KJ, ed. Computational Fluid and Solid Mechanics. Amsterdam: Elsevier; 2003:826-829.

36. Alves MA, Oliveira PJ, Pinho FT. A convergent and universally bounded interpolation scheme for the treatment of advection. Int $J$ Numer Methods Fluids. 2003;41:47-75.

37. Chiang TP, Sheu TWH, Wang SK. Side wall effects on the structure of laminar flow over a plane-symmetric sudden expansion. Comput Fluids. 2000;29:467-492.

38. Schreck E, Schäfer M. Numerical study of bifurcation in three-dimensional sudden channel expansions. Comput Fluids. 2000;29:583-593.

39. Williams PT, Baker AJ. Numerical simulations of laminar flow over a 3D backward-facing step. Int J Numer Methods Fluids. 1997;24:11591183.
40. Biswas G, Breuer M, Durst F. Backward-facing step flows for various expansion ratios at low and moderate Reynolds numbers. ASME $J$ Fluids Eng. 2004;126:362-374.

41. Alves MA, Oliveira PJ, Pinho FT. On the effect of contraction ratio in viscoelastic flow through abrupt contractions. J Non-Newt Fluid Mech. 2004;122:117-130.

42. Oliveira PJ, Pinho FT. Plane contraction flows of Upper Convected Maxwell and Phan-Thien-Tanner fluids as predicted by a finite-volume method. J Non-Newt Fluid Mech. 1999;88:63-88.

43. Oliveira PJ, Pinho FT. Numerical procedure for the computation of fluid flow with arbitrary stress-strain relationships. Num Heat Transfer B. 1999;35:295-315.

44. Walters K, Webster MF. The distinctive CFD challenges of computational rheology. Int J Numer Methods Fluids. 2003;43:577-596.

45. Sasmal GPA. Finite-volume approach for calculation of viscoelastic flow through an abrupt axisymmetrical contraction. J Non-Newt Fluid Mech. 1995;56:15-47.

46. Boger DV, Binnington RJ. Experimental removal of the re-entrant corner singularity in tubular entry flows. J Rheol. 1994;38:333-349.

47. Purnode B, Crochet MJ. Flows of polymer solutions through contractions. Part 1: Flows of polyacrylamide solutions through planar contractions. J Non-Newt Fluid Mech. 1996;65:269-289.

48. Quinzani LM, Armstrong RC, Brown RA. Birefringence and laserDoppler velocimetry (LDV) studies of viscoelastic flow through a planar contraction. J Non-Newt Fluid Mech. 1994;52:1-36.

Manuscript received Oct. 8, 2004, and revision received Mar. 12, 2005. 